\title{
Ultrastructural Basis for Interactions Between Central Opioids and Catecholamines. I. Rostral Ventrolateral Medulla
}

\author{
Teresa A. Milner, Virginia M. Pickel, and Donald J. Reis \\ Department of Neurology, Division of Neurobiology, Cornell University Medical College, New York, NY 10021
}

Opioids and some $\alpha_{2}$-adrenergic agonists are both known for their potent hypotensive actions following local application to the rostral ventrolateral medulla (RVL), in particular the region containing the $\mathrm{C} 1$ adrenergic neurons. We sought to determine whether coexistence and/or synaptic interactions might account for the commonality of cardiovascular responses to opioids and catecholamines in the RVL. Dual light and electron microscopic (EM) immunoperoxidase labeling of a rat monoclonal antibody against the opioid peptide Leucine ${ }^{5}$ (Leu $^{5}$ )-enkephalin and immunoautoradiographic localization of a rabbit antiserum against the catecholamine synthesizing enzyme tyrosine hydroxylase (TH) were examined in single sections through the RVL of adult colchicine-pretreated rats. Cross-reactivity of the enkephalin antibody was most intense with Leu ${ }^{5}$-enkephalin. Methionine ${ }^{5}$. enkephalin as well as dynorphin $A$, but not $\beta$-endorphin, were also recognized by the antisera. By light microscopy, the Leu ${ }^{5}$-enkephalin-like immunoreactivity (LE-LI) was identified by peroxidase reaction product in perikarya and processes. Most of the perikarya containing LE-LI were located dorsolaterally or ventromedially to those showing immunoautoradiographic labeling for TH. However, a few perikarya appeared to contain both LE-LI and TH-immunoreactivity (TH1) which were difficult to differentiate by light microscopy.

By EM, perikarya and dendrites immunoreactive for LE, TH, and both LE and TH were readily distinguishable. Perikarya and dendrites immunoautoradiographically labeled for TH alone were more numerous than those containing LE-LI or TH-I and LE-LI. Axon terminals also were immunolabeled either for one or both reaction products. However, the THlabeled neurons constituted one of the primary $(42 \%$ from a total of 118) targets of terminals containing LE-LI. Additionally, some of these terminals containing LE-LI shared a common target with TH-labeled terminals. These common target neurons contained either TH-I or TH-I and LE-LI. In most cases, the identified junctions were symmetric and the terminals with LE-LI (0.4-1.2 $\mu \mathrm{m}$ in diameter) contained either (1) a few small clear vesicles (scv's) and numerous intensely immunoreactive large (100-150 $\mathrm{nm}$ ) dense-core vesicles

\footnotetext{
Received Aug. 29, 1988; revised Nov. 7, 1988; accepted Nov. 11, 1988.

We would like to thank Dr. Shaun Morrison for his helpful suggestions on the manuscript and Ms. June Chan and Joan Chun for technical assistance. Supported by NIH Grants HI. 18974 , MH42834 (T.A.M.), DAO 46000 (V.M.P.) and a Career Development Award MH 00078 (V.M.P.)

Correspondence should be addressed to Dr. Teresa A. Milner, Division of Neurobiology, Cornell University Medical College, 411 East 69th Street, New York, NY 10021

Copyright (C) 1989 Society for Neuroscience $0270-6474 / 89 / 062114-17 \$ 02.00 / 0$
}

(dcv's); or (2) many scv's and from 0-6 dcv's of a somewhat smaller $(80-120 \mathrm{~nm})$ diameter. The latter type of terminal was more consistently dually labeled for $\mathrm{TH}$. The remaining terminals containing LE-LI formed synaptic junctions with unlabeled perikarya or dendrites $(32 \%)$, were in apposition to other unlabeled as well as TH or LE- and TH-containing terminals $(4 \%)$ or were without recognizable specializations within the plane of section (22\%). We conclude that opioid peptides and/or coexisting catecholamines in axon terminals in the RVL directly modulate and probably inhibit via their symmetric junctions the output of adrenergic neurons of the $\mathrm{C} 1$ cell group, as well as other dually labeled and unlabeled neurons. Inhibition of sympathoexcitatory adrenergic neurons projecting to the interomediolateral cell column of the spinal cord may be critical for the depressive cardiovascular effects of opioid transmitters in the RVL.

Neurons within the $\mathrm{Cl}$ region of the rostral ventrolateral medulla (RVL), possibly including the $\mathrm{Cl}$ adrenergic neurons themselves, are involved in the generation, maintenance, and reflex control of arterial pressure (AP). Such regulation is mediated via descending projections to the sympathetic preganglionic neurons in the intermediolateral cell column (IML) of the thoracic spinal cord (see Reis et al., 1988, for review). The vasomotor neurons in the RVL appear to be regulated by opioid peptides. Local application of several opioid peptides and/or their analogs, including $\mathrm{D}-\mathrm{Ala}^{2}-\mathrm{D}-\mathrm{Leu}^{5}$-enkephalin, dynorphin, and $\beta$-endorphin to the ventral surface of the medulla lying just beneath the $\mathrm{Cl}$ area or microinjections of these agents directly into the $\mathrm{Cl}$ area of the RVL, reduces AP and heart rate; naloxone, an opiate antagonist reverses these responses (Florez and Mediavilla, 1977; Hlorez et al., 1982; Punnen and Sapru, 1986; Willette et al., 1989). It is also of interest that the cardiovascular actions of these opiates and of a number of adrenergic agonists such as clonidine or $\alpha$-methyl noradrenaline when injected into the C1 area are comparable (Bousquet and Schwartz, 1983; Granata et al., 1986). Such observations, taken together with the fact that receptors of opiates and adrenergic receptors of the $\alpha_{2}$ subclass may be linked (Kunos et al., 1987), raise the prospect that opioid and adrenergic terminals may converge upon common targets in the RVL, conceivably adrenergic neurons of the Cl group.

That opioid and catecholaminergic neurons may interact within the $\mathrm{Cl}$ area gains support from the light microscopic immunocytochemical detection of opioid peptides in perikarya and processes topographically distributed in regions containing neurons immunoreactive for the adrenaline-synthesizing enzyme phenylethanolamine $N$-methyltransferase (PNMT) (Hökfelt et al., 1974, Elde et al., 1976; Sar et al., 1978; Williams and 
Dockray, 1983; Kalia et al., 1985a-c; Ruggiero et al., 1985; Murakami et al., 1987). We have recently shown by electron microscopy (EM) that adrenergic (i.e., PNMT-containing) terminals synapse directly on adrenergic neurons in the region (Milner et al., 1987a). Whether terminals containing opioid peptides also synapse upon $\mathrm{Cl}$ neurons - and, reciprocally, whether opioid-containing neurons in the RVL are innervated by the catecholaminergic neurons-is unknown.

Therefore, in the present investigation we examined the relationships between catecholamine and opioid neurons in the RVL of the adult rat by light and electron microscopy utilizing procedures for immunocytochemically localizing a rat monoclonal antibody against Leucine ${ }^{5}\left(\mathrm{Leu}^{5}\right)$-enkephalin and a rabbit antiserum against the general catecholamine synthesizing enzyme, tyrosine hydroxylase (TH) in single sections (Pickel et al., 1986). We demonstrate direct synaptic, coexistent and convergent relationships between neurons containing opioids and catecholamines in the RVL. These results suggest a cellular substrate within the RVL for the receptor-mediated influence of opiates on medullary control of the circulation and for a potential interaction with $\alpha_{2}$-adrenergic agonists in the same region.

\section{Materials and Methods}

Fixation and preparation of sections for immunocytochemistry. Studies were conducted in 15 adult male Sprague-Dawley rats (200-275 gm; Hilltop Lab Animals, Inc., PA). Animals were anesthetized with halothane $\left(2 \%\right.$ in $\left.100 \% \mathrm{O}_{2}\right)$ and colchicine $(100 \mu \mathrm{g} / 7.5 \mu \mathrm{l}$ saline) was stereotaxically injected into one lateral ventricle ( $\mathrm{I}$.jungdahl et al., 1978). The wounds were closed, and the animal removed from the stereotaxic frame and allowed to recover. Eighteen to $24 \mathrm{hr}$ later, the animals were deeply anesthetized with Nembutal $(50 \mathrm{mg} / \mathrm{kg}$, i.p.) and sequentially perfused through the ascending aorta with (1) $10 \mathrm{cc}$ of normal saline containing 1000 units of heparin; (2) $50-75 \mathrm{ml}$ of $3.75 \%$ acrolein (Polysciences) and $2 \%$ paraformaldehyde in $0.1 \mathrm{~m}$ phosplate buffer $(\mathrm{pH} 7.4)$; and (3) $200 \mathrm{ml}$ of $2 \%$ paraformaldehyde in $0.1 \mathrm{M}$ phosphate buffer. Coronal sections (30-40 $\mu \mathrm{m}$ thick) were cut on a Vibratome from the medulla oblongata at the level just caudal to the facial nerve to $1 \mathrm{~mm}$ caudal to the obex, a block containing the RVL (Armstrong et al., 1982; Ross et al., 1984b). Sections were collected in $0.1 \mathrm{M}$ phosphate buffer and pretreated as previously described (Milner et al., 1987a).

Antisera. A monoclonal rat-mouse antibody against $\mathrm{Leu}^{5}$-enkephalin obtained from Sera-I ab (Crawley Down, I JK) was tested for specificity by immunodot-blotting and by specific adsorption. For the immunodotblot procedure, several recognized members of the opioid family including Leu ${ }^{5}$-enkephalin, methionine ${ }^{5}\left(\right.$ Met $\left.^{5}\right)$-enkephalin, $\gamma, \beta$ and $\alpha$ endorphin, dynorphin A 1-8, 1-13, and 1-17 (Peninsula Labs) were dissolved in water to yield a concentration of $1 \mathrm{mg} / \mathrm{ml}$. The peptides were spotted on pieces of Whatman No. 1 filter paper held by a filtration manifold (Schleicher and Schuell). Each well in the filtration unit contained $10 \mu \mathrm{l}$ of one of the peptides at concentrations ranging from 0 to $1000 \mathrm{ng}$. The peptides were air-dried on the paper and exposed to paraformaldehyde vapors at $80^{\circ} \mathrm{C}$ for $1 \mathrm{hr}$. The papers were then immunocytochemically labeled with a 1:200 dilution of the monoclonal Leu ${ }^{5}$-enkephalin antibody according to the procedure of Larsson (1981).

For the adsorption control, $50 \mu \mathrm{g}$ of $\mathrm{Leu}^{5}$ - or Met ${ }^{5}$-enkephalin, $\beta$-endorphin, or dynorphin A 1-13 was added to separate test tubes containing $1 \mathrm{ml}$ of the primary antibody at the working dilutions. After $2 \mathrm{hr}$ of incubation at $37^{\circ} \mathrm{C}$, the complexes were removed by centrifugation and the supernatant was substituted for the primary antibody in the immunocytochemical labeling procedure on sections of tissue.

A polyclonal rabbit antiserum against trypsin-treated $\mathrm{TH}$ was produced and generously donated by Dr. Cory Abate (Department of Molecular Oncology, Roche Institute of Molecular Biology, Nutley, NJ 07110). The enzyme, purified from bovine adrenal medulla by methods described previously (Joh and Goldstein, 1973; Joh and Ross, 1983), was judged specific for TH by demonstration that (1) with Western blotting and immunostaining the antibodies in crude rat brain extract bound to a single band of protein corresponding to the molecular weight of TH $(60,000 \mathrm{Da})$; and (2) the antibody specifically inhibited the cat- alytic activity of ' $\mathrm{IH}$ in crude homogenates of rat brain (see Joh and Ross, 1983).

Dual labeling for TH and Leu'-enkephalin. Dual labeling for TH by immunoautoradiography and Leu ${ }^{5}$-enkephalin by the immunoperoxidase technique is a modification of the procedure of Pickel et al. (1986) and incorporates the peroxidase-antiperoxidase (PAP) method of Sternberger (1979). In brief, the sections were processed through the following series of incubations: (1) a 1:2000 dilution of TH-antiserum combined with a 1:200 dilution of Leus-enkephalin antibody for 18-24 hr; (2) three 10 min washes; (3) ${ }^{125}$ I-labeled donkey anti-rabbit immunoglobulin (IgG) (Amersham, Arlington Heights, IL) at a 1:100 dilution of a solution having a radioactive concentration of $100 \mu \mathrm{Ci} / \mathrm{ml}$ for $1 \mathrm{hr}$; (4) 10 min washes continued until the wash solution contained negligible radioactivity; (5) a 1:50 dilution of goat anti-mouse IgG (SternbergerMeyer) for $30 \mathrm{~min}$; (6) a 1:100 dilution of mouse PAP complex for 30 min; and (7) repeat of steps 5 and 6 (Ordronneau et al., 1981). The reaction product was demonstrated by incubation of the tissue with diaminobenzidine (DAB) and hydrogen peroxide. The incubations were carried out at room temperature with continuous agitation. All diluents and washes were with $0.1 \mathrm{M}$ Tris-saline $(\mathrm{pH} 7.6)$. The diluents also contained $1 \%$ BSA. Sections were transferred to $0.1 \mathrm{M}$ phosphate buffer and then were postfixed for $10 \mathrm{~min}$ in $1 \%$ glutaraldehyde in $0.1 \mathrm{M}$ phosphate buffer (De Mey et al., 1982).

Controls. To rule out nonspecific interactions between the 2 antisera (1) both the immunoperoxidase procedure for Leu ${ }^{5}$-enkephalin localization and the immunoautoradiographic procedure for $\mathrm{TH}$ localization were done separately; (2) $0.1 \mathrm{M}$ Tris-saline was substituted for the Leusenkephalin antibody; (3) $0.1 \mathrm{M}$ Tris-saline was substituted for the TH antiserum; and (4) both the enkephalin and TH antisera were omitted.

Processing for light and electron microscopic autoradiography. For light microscopy, the labeled sections were mounted on acid-cleaned slides previously coated with $0.25 \%$ gelatin. The sections then were processed for autoradiography according to the procedure of Cowan et al. (1972) as described in detail previously (Pickel et al., 1986). The autoradiographic exposure periods ranged from 4 to $15 \mathrm{~d}$. The final autoradiographic preparations were examined and photographed with a Nikon Microphot microscope using differential interference contrast (DIC) optics. Camera lucida drawings were made using a drawing tube attached to Nikon Labophot microscope.

For EM, the labeled sections were fixed for $2 \mathrm{hr}$ in $2 \%$ osmium tetroxide in $0.1 \mathrm{M}$ phosphate buffer, washed in phosphate buffer, and dehydrated. Sections were then flat-embedded with Epon 812 between 2 sheets of Aclar plastic (Masurovsky and Bunge, 1968). Regions known to contain TH-immunoreactive neurons in the RVL were selected using both the morphological boundaries established previously (Ruggiero et al., 1985; Milner et al., 1987a) and adjacent sections prepared for light microscopy. The tissues to be sampled for EM then were embedded with Epon 812 in Beem capsules.

EM autoradiography was performed by the procedure of Beaudet (1982) and Beaudet and Descarries (1987) as described previously by Pickel et al. (1986). Briefly, ultrathin sections $(50 \mathrm{~nm})$ were collected with a loop and deposited on slides previously coated with $2 \%$ parlodion in amyl acetate. The slides were counterstained with uranyl acetate and Reynolds lead citrate (Reynolds, 1963) and then coated with a silvergray layer of carbon (Varian Vacuum Evaporator). The slides were dipped in Ilford L-4 emulsion $\left(50^{\circ} \mathrm{C}\right)$ diluted 1:4 with water, air-dried, and exposed in light-proof boxes for periods of 3-6 months. The autoradiographs were developed $1.5-2$ min with Kodak Microdol-X developer $\left(16-17^{\circ} \mathrm{C}\right)$, rinsed in water, and fixed for $4 \mathrm{~min}$ in $30 \%$ sodium thiosulfate. The thin sections on the parlodion coating were collected on grids that were subsequently immersed for $3 \mathrm{~min}$ in amyl acetate.

The final autoradiographic preparations then were examined with a Philips 301 EM. EM analysis was conducted on 14 plastic-embedded, doubly labeled sections collected through the rostral portions of the RVL (see Fig. 2). These sections were selected based on optimal preservation of morphological details and maximal detection of both TH-I and LE-LI as observed by both light and electron microscopy.

Rationale for experimental design and controls. In the electron micrographs, immunoautoradiographic labeling for $\mathrm{TH}$ was more easily visualized than the peroxidase labeling for $\mathrm{Leu}^{5}$-enkephalin. This was due in part to the overlying emulsion layer that obscured the visualization of the peroxidase reaction product and also to the greater sensitivity of the ${ }^{125}$ I-marker. Thus, to insure that the analysis would not be biased towards one of the labels, only those micrographs that contained profiles labeled with both markers were used in the final analysis. 


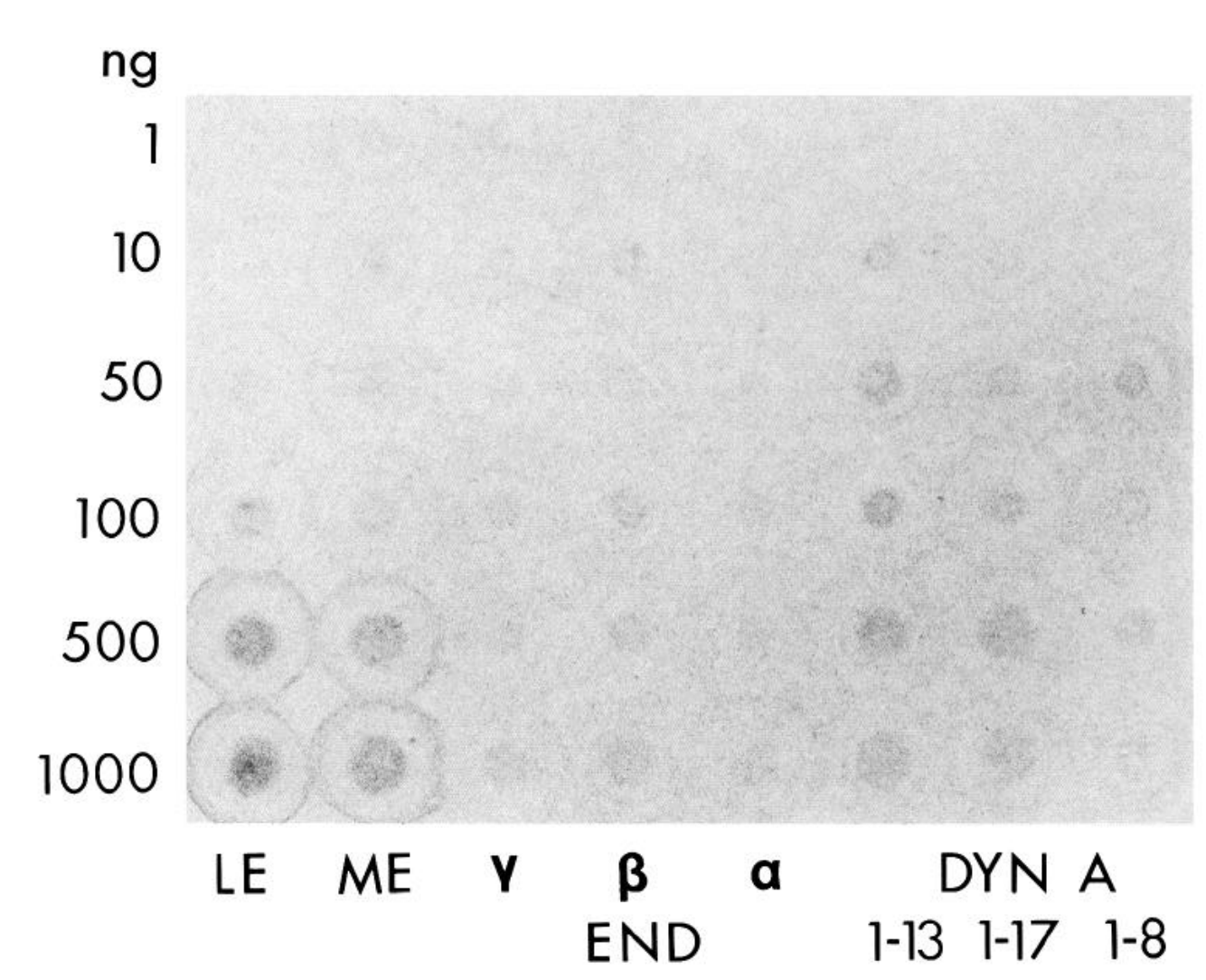

Figure 1. Immunodot-blots depicting the cross-reactivity between a 1:200 dilution of a monoclonal antibody to Leus-enkephalin and varying concentrations $(0-1000 \mathrm{ng})$ of $\mathrm{Leu}^{\mathrm{s}}$-enkephalin $(L E)$, Met $^{5}$-enkephalin $(M E), \gamma, \beta$, and $\alpha$ endorphin $(E N D)$, and dynorphin $\mathrm{A}(D Y N) 1-13,1-17$, and 1-8.
To differentiate specific autoradiographic labeling from background labeling in the EM autoradiographs, the profile of the suspected source of radiation was identified by the presence of silver grains in at least 2 and sometimes 3 or more adjacent thin sections. Additionally, a modification of the method of Salpeter et al., (1978) for quantitatively evaluating the distribution of silver grains was performed. For this, immunoautoradiographs were examined for the identity of cellular profiles that were the most probable sources of the observed silver grains indicative of the immunolabeling for TH. Qualitative inspection of photomicrographs suggested that the primary structures that contained silver grains were perikarya, dendrites, and terminals. This impression was verified by quantitatively analyzing 41 randomly chosen micrographs. In these, 569 silver grains were individually assessed with respect to their cellular origin. Of these, $94 \%$ had central points that were located within the area bounded by the plasmalemmas of perikarya, dendrites, and terminals, and $4 \%$ had central points that were located within a $150 \mathrm{~nm}$ radius of the cellular plasmalemmas. The remaining $2 \%$ of the silver grains had central points that were greater than $150 \mathrm{~nm}$ from the outer plasmalemma of the labeled profiles.

Within single sections, the individual perikarya usually exhibited 2065 silver grains within the boundaries of their plasmalemma, whereas the larger (proximal) dendrites had 4-15 silver grains and the smaller dendrites, dendritic spines, and terminals usually had fewer than 5 grains each. Thus, in order to detect silver grains in the smallest structures, we reviewed only profiles labeled in at least 2 serial sections.

\section{Results}

\section{Cross-reactivity of Leu ${ }^{5}$-enkephalin antibody}

The specificity of the Leus-enkephalin antibody with respect to cross-reactivity with other opioid peptides was assessed by immunodot-blotting. As seen in the immunodot-blot in Figure 1, the Leus-enkephalin antibody primarily reacted with the corresponding peptide. However, it also cross-reacted with Met $^{5}$ enkephalin. A limited cross-reaction was also observed with all 3 fragments of dynorphin A. Additionally, the immunocytochemical reaction was abolished by preadsorption of the $\mathrm{Leu}^{5}$ enkephalin antibody with high concentrations of either $\mathrm{Leu}^{5}$ or
Met ${ }^{5}$-enkephalin. The reaction only appeared to be partially diminished following adsorption with dynorphin A 1-13 and unaltered by adsorption with $\beta$-endorphin. In this context, labeling for $\mathrm{Leu}^{\mathrm{s}}$-enkephalin is referred to as LE-LI to reflect the antigen used for production of the antibody and the cross-reaction with $\mathrm{Met}^{5}$-enkephalin and dynorphin A fragments.

\section{Combined localization of immunoreactivity for LE and TH}

\section{Light microscopy}

Within the RVL, LE-LI was detected in neuronal perikarya that were located either dorsolateral or ventromedial to the neurons with TH-I (Figs. 2, 3, 4a). A few of the neurons showing LELI were distributed along the medullary surface ventral to the RVL (Fig. 3): Some of the soma containing TH-I also appeared colabeled for LE. However, by light microscopy the intensity of the black autoradiographic labeling obscured the visualization of the brown peroxidase reaction product within the same cell. Hence, it was not possible to fully estimate the prevalence of colabeling; the impression is, however, that it was relatively uncommon.

Numerous LE-containing varicose processes, often interspersed between bundles of white matter, were observed in proximity to TH-labeled perikarya and processes (Figs. 3, 4b). Occasionally, a TH-labeled process was found in close proximity to perikarya containing LE-LI (Fig. 4c). Perikarya and processes with LE-LI were in close proximity to TH-labeled cells throughout rostral and caudal portions of the RVL.

\section{Electron microscopy}

Ultrastructural localization of $L E-L I$. To examine the ultrastructural relationship between neurons with LE-LI and adrenergic neurons, portions of the rostral RVL were sampled for EM (Fig. 2). At this medullary level, there is no evidence for TH- 
- LEU-ENK $\circ \mathrm{TH}$

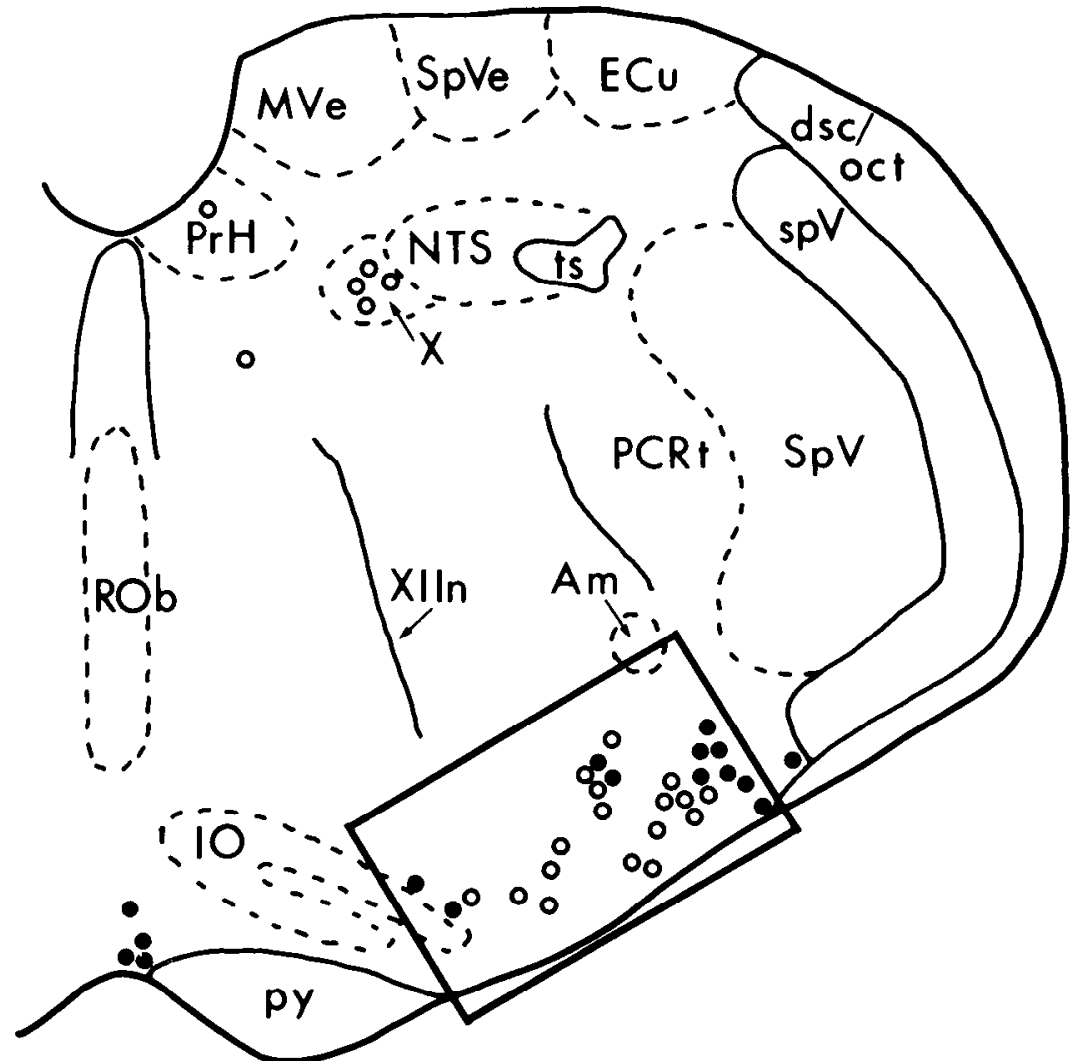

Figure 2. Camera lucida drawing of a coronal section through the medulla oblongata showing the distribution of neurons containing LE-LI (dots) and TH-I (open circles). The boxed area corresponds to the region of the RVL sampled for electron microscopy. Am, n. ambiguus; $d s c / o c t$, dorsal spinocerebellar tract/olivocerebellar tract; $E C u$, external cuneate $\mathrm{n}_{\text {.; }} I O$, inferior olive; $M V e$, medial vestibular $\mathrm{n}$; $N T S$, nucleus of the solitary tract; $P C R t$, parvicellar reticular n.; PrH, prepositus hypoglossal n.; $p y$, pyramidal tract; $R O b$, raphe obscurus; $s p V$, spinal tract of trigeminal nerve; $S p V, \mathrm{n}$. of the spinal tract of trigeminal nerve; $S p V e$, spinal vestibular n.; $t s$, solitary tract; $X$, dorsal motor $\mathrm{n}$. of vagus; XIIn, root of the hypoglossal nerve.

containing neurons in the RVL that do not contain PNMT; hence, the population of TH-labeled neurons corresponds to the C1 cell group (Armstrong et al., 1982; Kalia et al., 1985a, b; Ruggiero et al., 1985).

LE-LI was localized in perikarya, dendrites, axons, and axon terminals (Figs. 5-9). Perikarya, which were rare, were medium sized (20-25 $\mu \mathrm{m}$ diameter), elongated or round, and contained abundant cytoplasm. The nucleus was unlabeled and had a slightly infolded nuclear membrane. Large dense-core vesicles (dcv's), rough endoplasmic reticulum, Golgi apparatus, lysosomes, and coated vesicles were among the distinguishable organelles.

Dendrites with LE-LI ranged from large (1.2-3.0 $\mu \mathrm{m}$ diameter) to small (0.4-1.2 $\mu \mathrm{m}$ diameter), with the largest lying closest to the somata. Proximal dendrites were similar to the perikarya in that they contained mitochondria, ribosomes, rough endoplasmic reticulum, and microtubules (Fig. $5 c$ ). Moreover, some of the labeled dendrites also contained large dcv's (Fig. 8, $a, b$ ) and/or TH-I (Fig. 9c).

The terminals containing LE-LI ranged from 0.4 to $1.2 \mu \mathrm{m}$ in diameter, contained a few mitochondria, and could be divided into 2 types depending on their vesicular content. The first type contained a few oval, small $(25-50 \mathrm{~nm})$, clear vesicles (scv's) and from 6 to 12 large $(100-150 \mathrm{~nm})$ dcv's (Fig. $5 b$ ). These dcv's were found throughout the terminal and were intensely peroxidase-labeled throughout their central lumen. The second type of terminal with LE-LI was more abundant and contained many scv's and from 0 to 6 smaller $(80-100 \mathrm{~nm})$ dcv's (Figs. $5 a ; 6-9)$. In this latter type, the scv's were rimmed with reaction product and aggregated toward synaptic junctions on dendrites, whereas the dcv's were usually located distal to the synaptic junction. A few $(n=5)$ of both types of terminals with LE-LI also contained TH-I (Figs. 6; 9, $a, b$ ).

Synaptic relations of neurons containing $L E-L I$. The majority of perikarya and dendrites with $L E-L I$ received synaptic contacts from terminals lacking either LE-LI or TH-I (Fig. $5 c$; schematically shown in Fig. 10). The junctions formed by unlabeled terminals were of both the symmetric and asymmetric type. The unlabeled terminals contained mitochondria, numerous scv's and a few dcv's. The enkephalin-labeled perikarya and dendrites were usually postsynaptic to more than one unlabeled terminal. Dendrites with LE-LI were contacted rarely by terminals containing either $L E-L I$ or $T H-I$ (Figs. $8 a, b ; 9 c$ ). Both types of labeled terminals principally formed symmetric junctions, although asymmetric junctions also were seen between terminals and dendrites containing LE-LI.

A quantitative evaluation of the neural associations of 118 enkephalin-labeled terminals demonstrated that $42 \%$ ( 49 out of 118) formed synaptic contacts or appositions with $T H$-immunoreactive perikarya and dendrites (schematically shown in Fig. $10)$. The somatic synapses $(n=4)$ formed between terminals with LE-LI and TH-labeled perikarya were characterized by symmetric membrane specializations. More commonly ( $92 \%$ or 45 out of 49), the terminals containing LE-LI formed associa- 
*: $\| W_{1}$

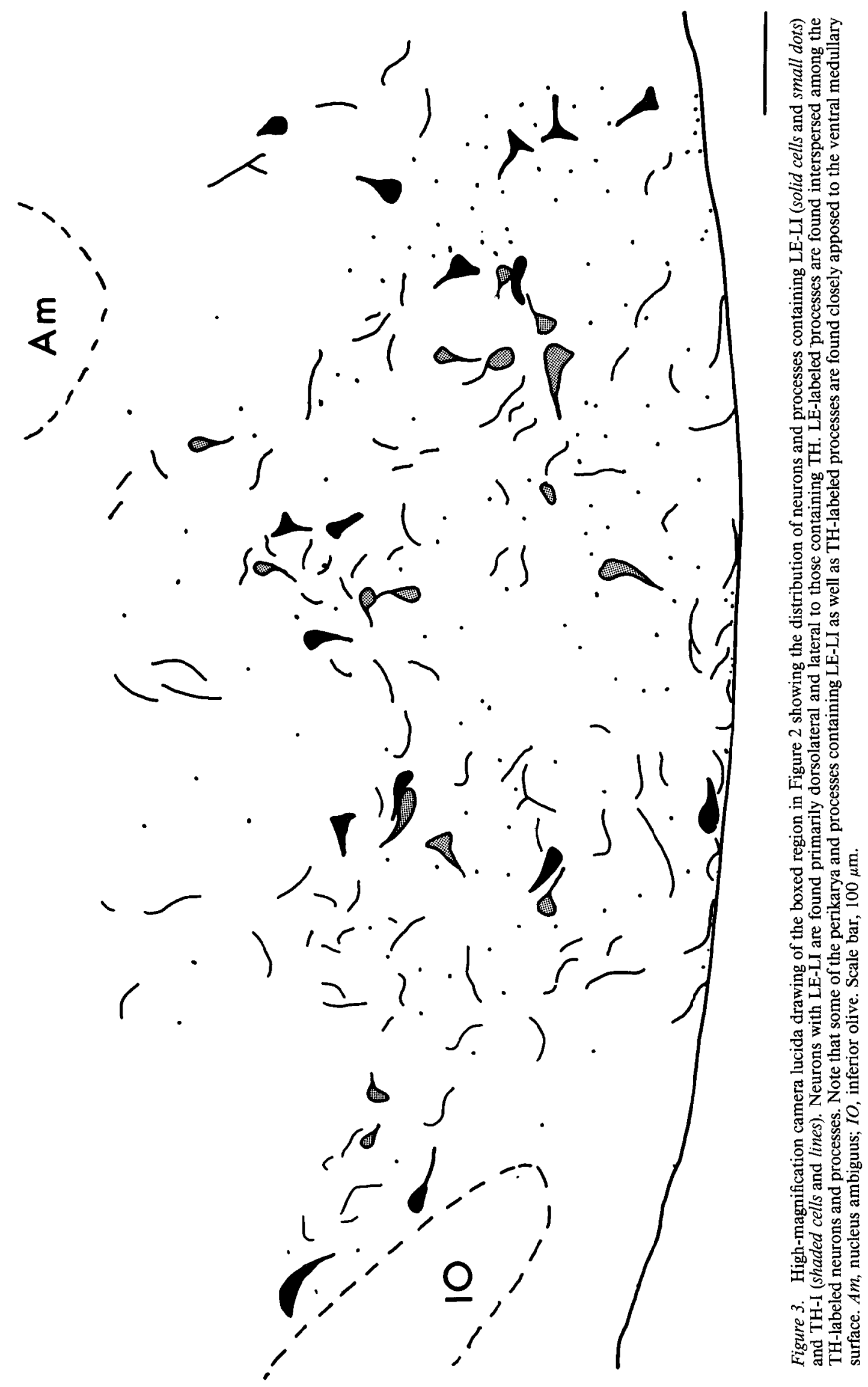




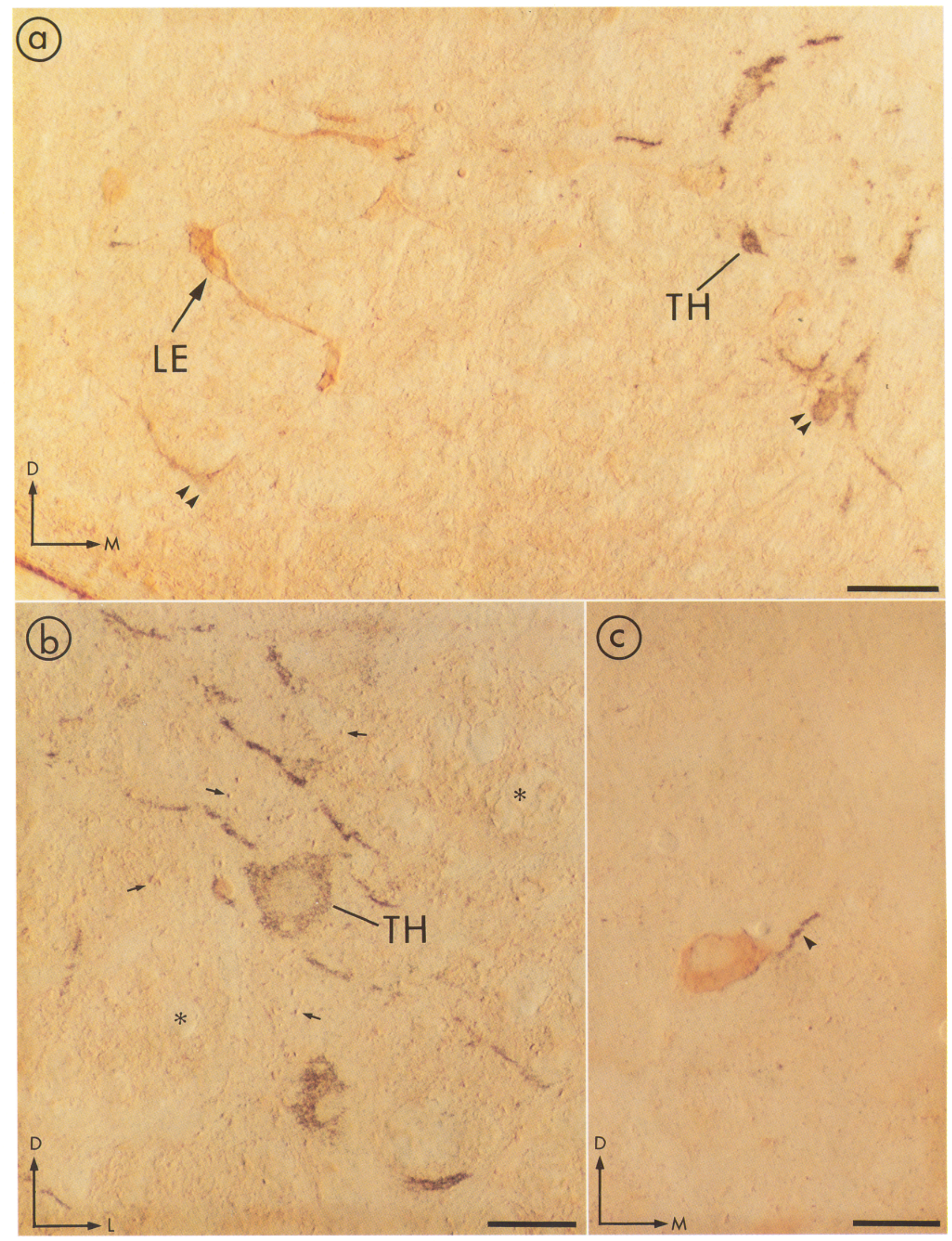

Figure 4. Light microscopic localization of Leus-enkephalin and TH immunoreactivities in the RVL of a colchicine-pretreated rat. Perikarya and processes with the immunoperoxidase product for LE-LI are brown, whereas perikarya and processes showing immunoautoradiographic label for TH are black. $a$, Perikarya with LE-LI are found lateral to the TH-labeled cell bodies. Some of the neurons with immunoautoradiographic labeling for TH also appeared to contain immuno peroxidase labeling for LE (double arrowheads). $b$, Many small varicose processes with LE-LI (small arrows) are found interdispersed among TH-labeled perikarya and processes and bundles of myelinated axons (asterisks). c, A small TH-immunoreactive process (arrowhead) is found adjacent to a perikarya containing LE-LI. Arrows indicate orientation: $D$, dorsal; $L$, lateral; $M$, medial. Autoradiographic exposure $=5 \mathrm{~d}$. Scale bars, $50 \mu \mathrm{m}$. 


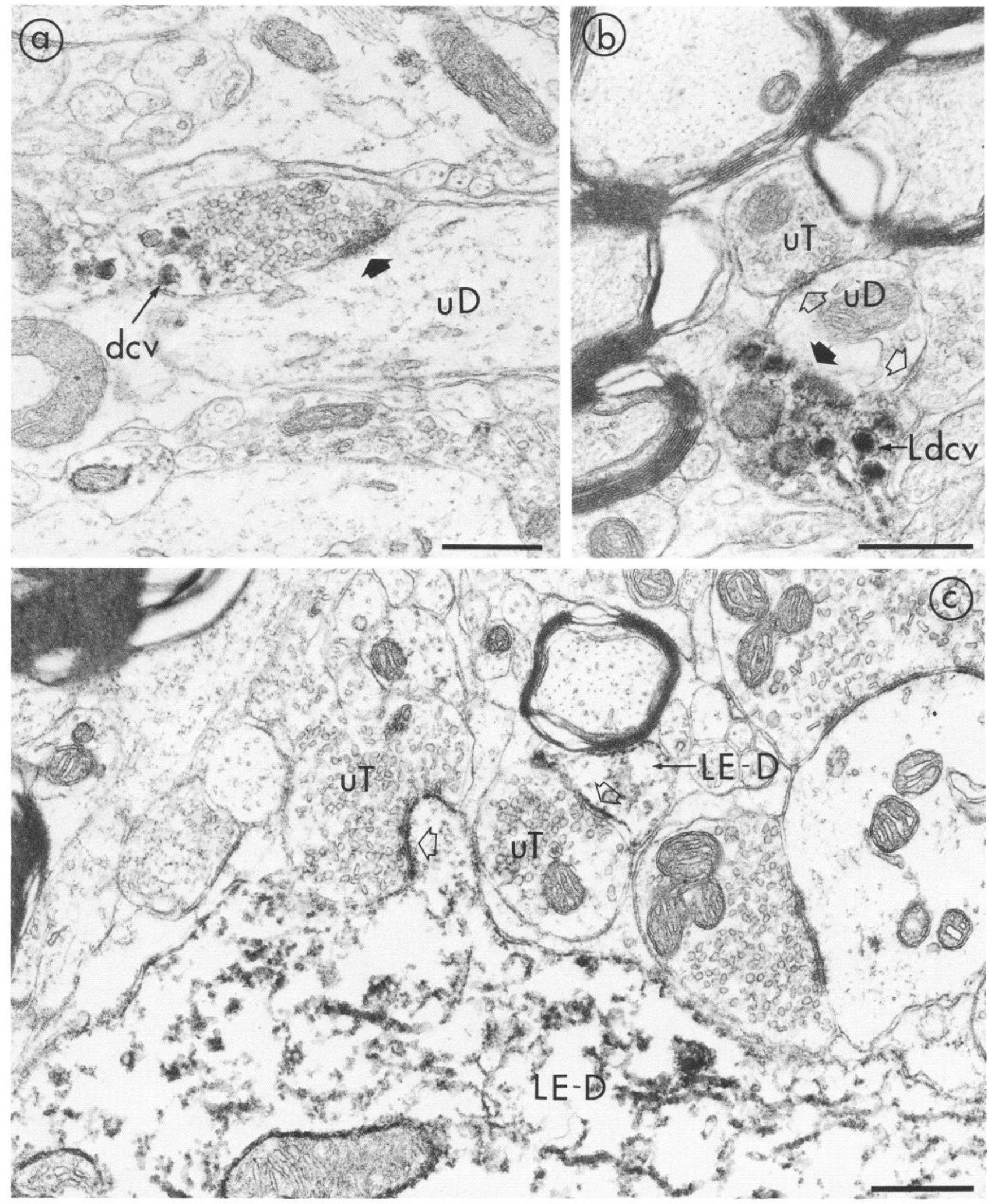

Figure 5. Associations of LE-containing terminals and dendrites with unlabeled processes. $a$, The most commonly observed type of terminal with LE-LI contains numerous small clear vesicles $(s c v)$ and a few large dense core vesicles $(d c v)$ located away from the synaptic junction. In this case, the labeled terminal forms a symmetric synaptic junction (closed arrow) with an unlabeled dendrite $(u D)$ ). $b$, The rarer type of terminal with LELI contains numerous large dcv's throughout. This terminal forms a symmetric synapse (closed arrow) with an unlabeled dendrite $(u D)$ which also receives a synapse (open arrow) from an unlabeled terminal. $c$, Two LE-labeled dendrites $(L E-D)$ receive symmetric synaptic contacts (open arrows) from unlabeled terminals $(u T)$. Scale bar, $0.5 \mu \mathrm{m}$. 
tions with TH-labeled dendrites. Of these, one-third were on the shaft of large (1.5-3.0 $\mu \mathrm{m})$ TH-labeled dendrites (Fig. 6); the remaining two-thirds were on the shafts and spines of smaller $(0.5-1.2 \mu \mathrm{m}$ ) TH-labeled dendrites (Figs. $7 a, b ; 8, a, b ; 9 c)$. Of the total contacts between enkephalin-labeled terminals and dendrites with TH-I, $48 \%$ were of the symmetric, and $14 \%$ were of the asymmetric type and the remainder lacked recognizable membrane specializations in the plane of section analyzed. Contacts from more than one LE-containing terminal on the TH-labeled dendrites were usually not seen in single sections. However, convergence on the TH-labeled dendrites from terminals containing LE-LI and cither other unidentificd (unlabeled) axon terminals or terminals containing TH-I $(n=3)$ were seen in single sections (Fig. 7, $a, b$ ).

Relatively equal proportions $(32 \%$ or 38 out of 118$)$ of the terminals exhibiting LE-LI formed synaptic junctions or appositions with either soma or dendrites which were without detectable levels of immunoreactivity (schematically shown in Fig. 10). Somatic synapses were formed rarely by the LE-labeled terminals and were characterized by symmetric membrane specializations. The majority $(n=33)$ of the synapses formed by the terminals with LE-LI were on the shafts of unlabeled dendrites (Figs. 5, $a, b ; 7, c, d$ ), whereas the remainder were on unlabeled dendritic spines. Of the contacts formed between terminals containing LE-LI and unlabeled dendrites, $73 \%$ were of the symmetric type and $16 \%$ were of the asymmetric type; the rest lacked a recognizable membrane specialization in the plane of section analyzed.

In the remaining $26 \%$ (31 out of 118 ) of the terminals with LE-LI, the majority lacked any apparent synaptic density within the plane of section analyzed and were separated from the neuropil by glial processes (Fig. 9, $a, b$ ). However, direct appositions between 2 axon terminals not separated by glial processes were sometimes ( 5 out of 118 ) observed. These included appositions with other unlabeled terminals as well as those containing TH-I or TH-I and LE-LI. In these cases, the labeled terminals were in direct apposition to each other without any glial intervention (Fig. 9, $a, b$ ).

\section{Discussion}

Using a recently developed methodology for dual labeling, we have established the ultrastructural morphology of neurons with LE-LI and their synaptic and intracellular relations with catecholaminergic and non-catecholaminergic neurons in the RVL.

\section{Methodological considerations}

\section{Cross-reactivity of the Leu'-enkephalin antibody}

The immunoblot and adsorption controls in the present study demonstrated that the monoclonal antibody against $\mathrm{Leu}^{5}$-enkephalin cross-reacted extensively with this peptide and to a lesser extent with Met $^{5}$-enkephalin and all dynorphin A fragments. We have consistently referred to the reaction product as LE-LI to account for possible cross-reactivity with pro-enkephalins, pro-dynorphins, or other unidentified opioid peptides. The cross-reactivity with dynorphin A might have been expected since dynorphin contains several Leus-enkephalin sequences (Goodman et al., 1983; Smith and Lee, 1988), and in certain regions of the CNS $\mathrm{Leu}^{5}$-enkephalin may be derived from prodynorphin rather than pro-enkephalin (Zamir et al., 1984; Zamir and Quirion, 1985). Moreover, in the RVL the distribution of LE-LI and dynorphin-like immunoreactivity is nearly identical (Fallon and Leslie, 1986).

\section{Dual labeling technique}

In the present study, we have used a technique for visualizing 2 antigens by combining peroxidase and immunoautoradiographic labeling of antisera from separate species. These have been processed in Vibratome sections immunocytochemically labeled prior to embedding in plastic. While it is possible to utilize 2 antisera from the same species for double labeling, as we have done in localizing substance $P(S P)$ and catecholaminesynthesizing enzymes in the medial nuclei of the solitary tracts (m-NTS) (Pickel et al., 1986) and in the RVL (Milner et al., $1988 \mathrm{a}$ ), the employment of antisera from 2 different species has advantages in that differential labeling is not dependent on variations in dilution of the primary antisera or the sensitivities of the labeling methods (Pickel et al., 1986). This approach has been used by us to localize TH and SP in the RVL and nucleus accumbens (Milner et al., 1988a; Pickel et al., 1988a) or TH and GABA in the nucleus accumbens (Pickel et al., 1988b). In this and previous studies, use of higher concentrations (1:2000 vs 1:30,000) of the $\mathrm{TH}$-antiserum and a highly sensitive (doublebridging PAP vs conjugated peroxidase) peroxidase labeling significantly improved the dual detection of TH and LE in this study over our earlier method (Ordronneau et al., 1981; Pickel et al., 1986). The major improvements include shorter autoradiographic exposure periods (4 vs 9 months) for electron micrographs and dense PAP-reaction product.

In larger perikarya and dendrites, the specificity of immunoautoradiographic labeling was readily verified by the presence of label in adjacent sections (Pickel et al., 1986). Spread of radiation away from the source (Salpeter et al., 1978) can lead to false identification of immunoautoradiographic grains in smaller processes such as dendritic spines and axon terminals. Both the type of photographic emulsion and radioactive isotope used can influence this spread (as visualized by silver grains) (Salpeter et al., 1977). In tissue fixed with osmium tetroxide and counterstained with uranyl acetate, the resolution for ${ }^{125} \mathrm{I}$ labeled material using Ilford-L4 emulsion is approximately 150 $\mathrm{nm}$ (Salpeter et al., 1978). Thus, even small $(0.1 \mu \mathrm{m}) \mathrm{TH}$-labeled profiles are large enough to allow tentative identification of the radiation source in single sections without counting the grains over each profile. However, quantitative analysis of silver grains in the present study revealed a selective accumulation of silver grains over neuronal perikarya, dendrites, and terminals. The identity of silver grains over the same profile in serial sections also helped to eliminate false-positives due to random background labeling.

\section{Labeling methods and catecholaminergic markers}

Neurons labeled for TH in the RVL by immunoautoradiography were identical in morphology and synaptic associations to those labeled by the PAP method (see Milner et al., 1989). In the absence of dense peroxidase reaction product, cytoplasmic organelles were more easily visualized in the autoradiographs. However, the silver grains did not appear to be clearly associated with any subcellular organelle.

It seems most likely for several reasons that TH-LI perikarya and dendrites in the RVL are contained exclusively in adrenergic and not in noradrenergic neurons. First, in the RVL all neurons containing TH and PNMT are coextensive and all neurons containing TH also contain PNMT (Hökfelt et al., 1974; Armstrong et al., 1982; Kalia et al., 1985a-c; Ruggiero et al., 1985; Tucker et al., 1987). Second, the morphological characteristics of peri- 


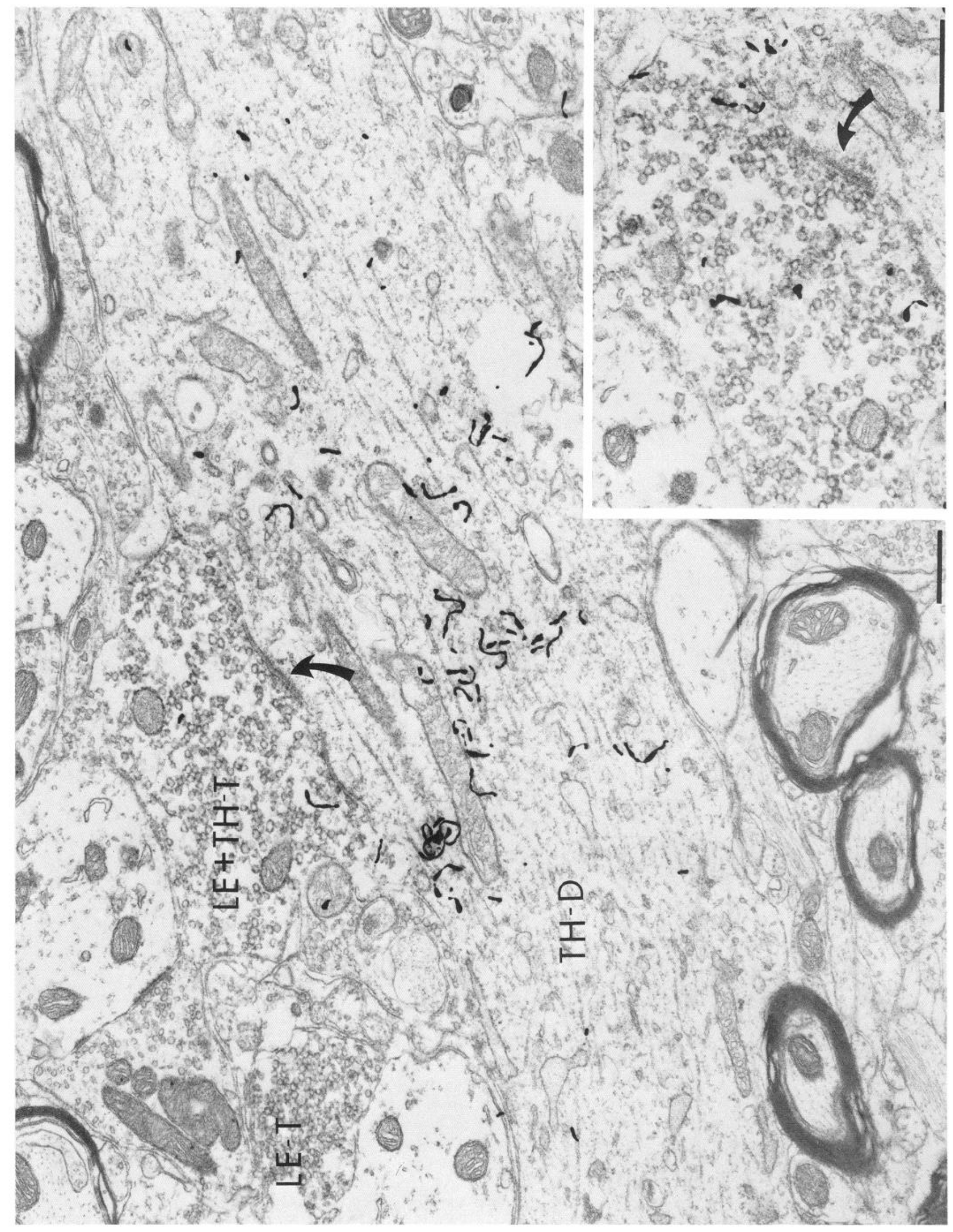


karya and dendrites containing TH-I are identical to those neurons immunoreactive for PNMT (Milner et al., 1987a). Third, as shown in our study of the relationships between SP-containing neurons and catecholaminergic neurons in the RVL (Milner et al., 1988a), the distribution and types of synaptic associations formed by SP-labeled terminals on catecholaminergic neurons containing TH-I are identical to those on neurons with PNMTI. On the other hand, axons and terminals containing TH-I could arise from either noradrenergic neurons of the $\mathrm{A} 1, \mathrm{~A} 2, \mathrm{~A} 5$, and A6 cell groups or from adrenergic neurons of the $\mathrm{C} 2$ cell group which are known to innervate the RVL (Andrezik et al., 1981; Ruggiero et al., 1985). To be certain that the TH-labeled neurons in the RVL are the $\mathrm{Cl}$-adrenergic neurons, PNMT antiserum was recently co-localized with TH in the RVL in a similar duallabeling study (T. A. Milner, unpublished observations).

\section{Subcellular localization of LE-LI}

The RVL contains numerous axon terminals with LE-LI providing morphological evidence that opioid peptides may act within the RVL as a synaptic modulator. The most commonly encountered type of terminal contained numerous scv's and from 0 to 6 large dcv's, a similar vesicular content to that described previously for enkephalin-containing terminals in area postrema and m-NTS (Pickel et al., 1979; Armstrong et al., 1981; Voorn and Buijs, 1983), in the superficial layers of the spinal cord (Hunt et al., 1980) and in the spinal trigeminal nucleus (Priestley, 1981). The presence of dcv's amidst unlabeled smaller vesicles raises the prospect that enkephalin or a related peptide may be co-localized in these terminals with other transmitters. Our observation that some of the terminals with LE-LI also contained TH-I indicates that catecholamines are one of the coexisting transmitters in the RVL. While this is the first ultrastructural evidence for coexistence of LE-LI and TH-I in central terminals, this phenomenon is well established in the periphery. In rat vas deferens subjected to differential and sucrose density gradient centrifugation, enkephalin activity paralleled that of noradrenaline in the denser region of the gradient in which "heavy" or large dcv's were present (Neuman et al., 1984; De Potter et al., 1987). Additionally, the large dcv's in peripheral sympathetic nerves show selective accumulations of gold particles indicative of $\mathrm{Met}^{5}$-enkephalin immunoreactivity (De Potter et al., 1987). [Synaptic vesicles and their relation to co-storage of opiates and catecholamines are discussed in more detail in the report by Pickel et al. (1989) in the medial NTS where similar co-localization of LE-LI and TH-I in the same terminal was seen.]

The origin of terminals with LE-LI in the RVL is not entirely certain. Probably some, if not all, of the labeled terminals of both types are derived from intrinsic opioid neurons in the RVL. Perikarya containing either $\mathrm{Leu}^{5}$ - and $\mathrm{Met}^{5}$-enkephalin were detected in this and other studies (Elde et al., 1976; Hökfelt et al., 1977; Sar et al., 1978; Williams and Dockray, 1983; Fallon and Leslie, 1986; Murakami et al., 1987). The possibility exists, however, that some of the LE-LI may be contained in axons arising from neurons outside of the RVL. At least 3 regions projecting to the RVL, namely, the NTS, the nucleus raphe, and the lateral hypothalamus (Andrezik et al., 1981; Ross et al., 1985), contain neurons with LE-LI (Williams and Dockray, 1983). That the projection from the NTS to the RVL might be in part enkephalinergic is suggested by the findings that those regions of the m-NTS that give rise to afferent projections to the RVL (Ross et al., 1985) correspond to those which contain perikarya with either LE-LI or LE-LI and TH-I. Moreover, perikarya in this region of the NTS contain numerous dev's that are similar in morphology to those observed in LE-labeled terminals within the RVL (Pickel et al.; 1989). Combined immunocytochemical labeling of LE-LI and anterograde and/or retrograde transport methods are needed to establish the source of the enkephalin-labeled terminals in the RVL.

\section{Interactions between opioids and catecholamines}

In view of the relative sparsity of opioid terminals in the RVL in general, compared with regions such as the m-NTS (Elde et al., 1976; Finley et al., 1981; Fallon and Leslie, 1986), the prominent innervation of catecholaminergic neurons by terminals containing LE-LI suggests that this input is highly directed and may reflect an important site for a functional interaction between opioids and catecholamines.

\section{Direct synaptic input to catecholaminergic neurons}

The present study demonstrates that the catecholaminergic neurons in the $\mathrm{Cl}$ area of the RVL are one of the major targets of terminals with LE-LI (see summary diagram, Fig. 10). The results suggest, moreover, that a significant fraction of the action of enkephalin in the RVL is mediated directly through synapses with catecholaminergic neurons.

The majority of the observed synaptic associations between LE-containing terminals and TH-immunoreactive perikarya and dendrites were symmetric (Gray type II), whereas the minority were asymmetric (Gray type I). Asymmetric synapses are believed to mediate excitation based largely on the detection of enriched populations of thickened postsynaptic densities in regions of the brain containing higher proportions of excitatory synapses; similar analysis suggests that symmetric synapses mediate inhibition (Uchizono, 1965; Cohen et al., 1982). For example, terminals containing the inhibitory neurotransmitter GABA (Krnjevic', 1976) form synapses that are exclusively symmetric in several regions of the brain, including the RVL, when examined under similar labeling conditions as used in the present study (Milner et al., 1987b; Pickel et al., 1988b). Thus, these findings suggest that enkephalin or a related peptide in the RVL synaptically inhibits catecholaminergic, most likely adrenergic neurons of the $\mathrm{C} 1$ cell group.

Moreover, this finding adds further insights to the action of opioids in the RVL on the control of AP. It is now well established that local application of several opioid peptides and/or their analogs-including D-Ala ${ }^{2}-\mathrm{D}-\mathrm{Leu}^{5}$-enkephalin, dynorphin,

\section{$\leftarrow$}

Figure 6. Association of LE-labeled terminal with TH-containing dendrite. A terminal with both LE-LI and TH-I $(L E+T H-T)$ forms a symmetric synapse (curved arrow) with a large TH-labeled dendrite $(T H-D)$. Inset, higher magnification of the dually labeled terminal from an adjacent section. Note that a terminal with only LE-LI is found in the same vicinity as the dually labeled terminal. Autoradiographic exposure, 6 months. Scalc bar, $0.5 \mu \mathrm{m}$. 


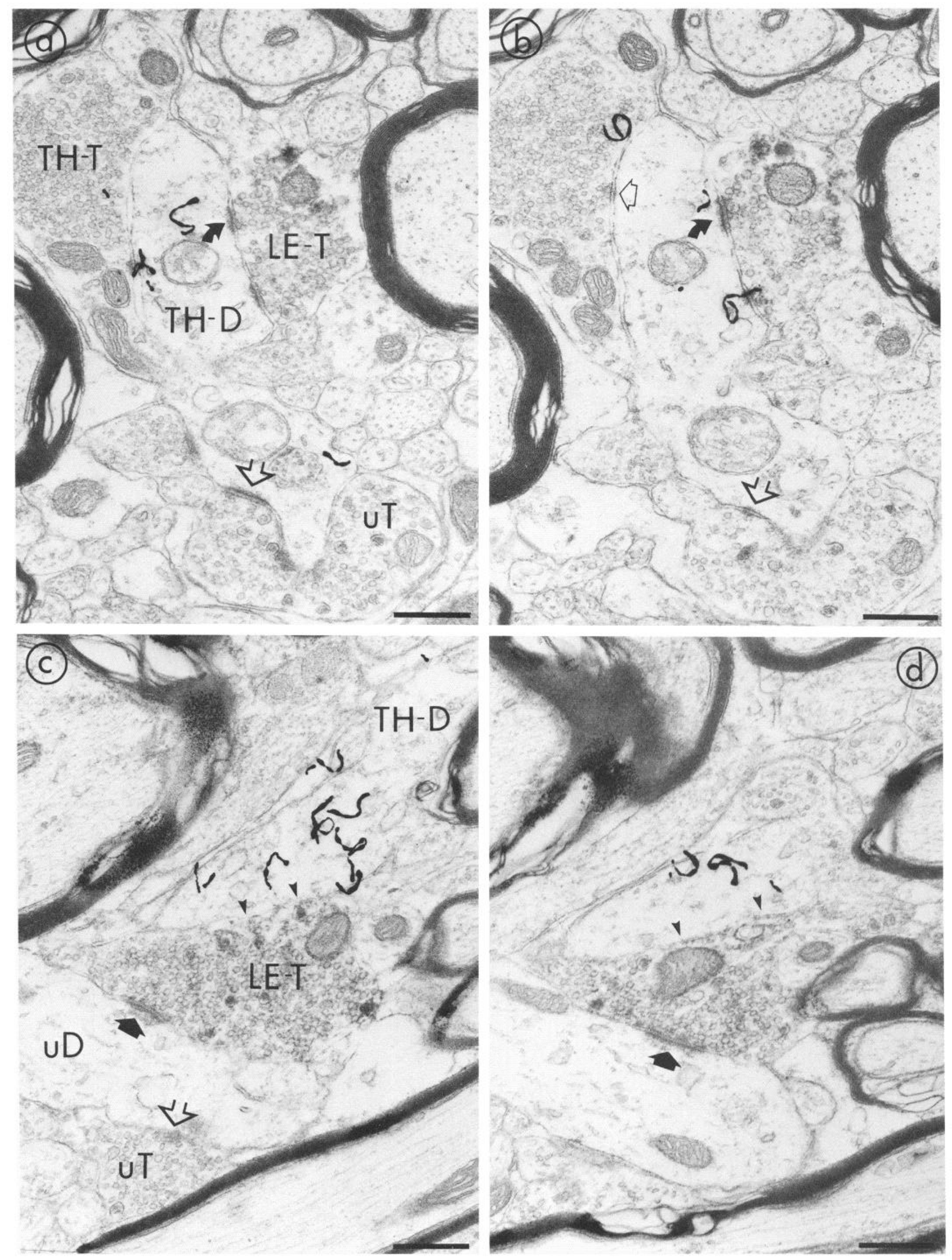



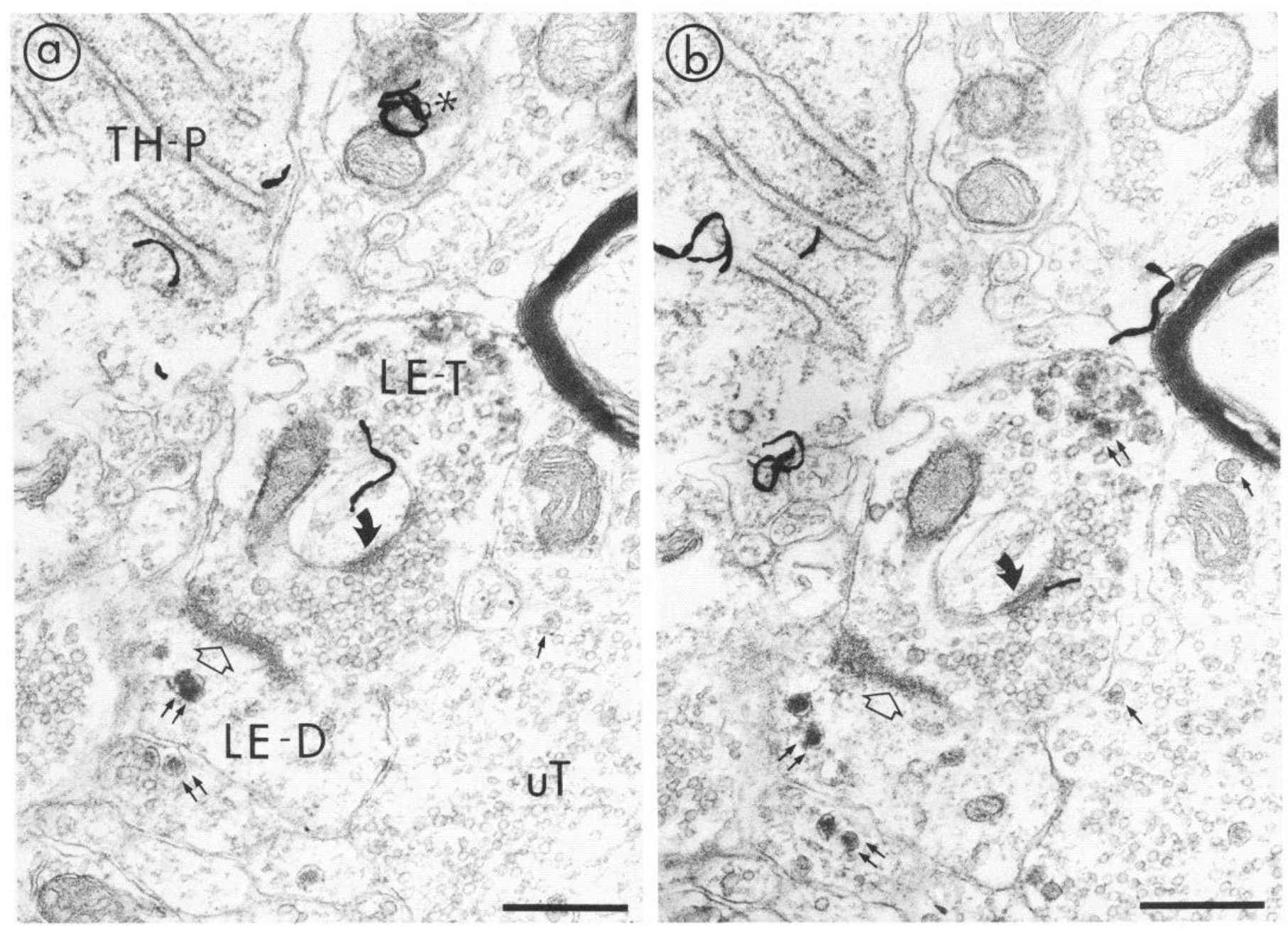

Figure 8. Multiple associations of LE-containing terminals. $a$ and $b$, Serial electron micrographs show a terminal with LE-LI ( $L E$-T) that forms a symmetric synapse (solid arrow) with a TH-containing spinous process. Whether the spine is dendritic or somatic in origin could not be determined; however, a perikarya containing TH-I (TH-P) was found in the same vicinity. The LE-labeled terminal also forms an asymmetric synapse (closed arrow ) with a dendrite that is immunoreactive for $\operatorname{LE}(L E-D)$. The presence of peroxidase labeling in the dendrite is clearest following comparison of the dense-core vesicles in neighboring processes (small double arrows vs small single arrows). Autoradiographic exposure, 5 months. Scale bars, $0.5 \mu \mathrm{m}$.

and $\beta$-endorphin-into or adjacent to the $\mathrm{Cl}$ area lowers $\mathrm{AP}$ and heart rate; these responses are blocked by naloxone (Florez and Mediavilla, 1977; Florez et al., 1982; Punnen and Sapru, 1986; Willette et al., 1989). Moreover, the $\mathrm{C} 1$ cell group appears to correspond to the reticulospinal sympathetic premotor neurons of the medulla essential for maintaining resting levels of AP mediating a number of critical cardiovascular reflexes (see Reis et al., 1988). The demonstration that opioid neurons synapse on these neurons and that the interaction is presumably inhibitory suggests that the action of opioids to reduce the activity of these neurons is direct and not mediated via an interneuron.

The fact that many of the terminals synapsing upon cate- cholaminergic perikarya and dendrites in the RVL were devoid of LE-LI indicates that other neurotransmitters regulate the activity of these neurons. It is likely, as we have recently demonstrated by electron microscopy, that many of the terminals which lack LE-LI may contain GABA or SP (Milner et al., 1987b; Milner et al., 1988a), a few contain catecholamines, either noradrenaline and/or adrenaline (Milner et al., 1987a), while others contain ACh (Milner et al., 1988b). The recent observations by light microscopy that catecholaminergic neurons in the RVL are innervated by terminals containing oxytocin (Hancock and Nicholas, 1987) suggest that this peptide may also play a regulatory role in the area.

Our observations in the RVL support the abundant evidence

Figure 7. Associations of LE-labeled terminals with TH-labeled terminals and dendrites. $a$ and $b$, Serial electron micrographs show a terminal with LE-LI $(L E-T)$ that forms an asymmetric synapse (solid arrow) with a small TH-containing dendrite $(T H-D)$ that also receives a symmetric synapse (closed, clear arrow) from a TH-labeled terminal and a synapse (solid arrow) from an unlabeled terminal $(u T)$. Although the TH-containing terminal only contains one grain in each micrograph, the terminal was consistently labeled in a third section (not shown). $c$ and $d$, Serial electron micrographs depict a LE-labeled terminal that forms an asymmetric synapse (open, clear arrow) with a small unlabeled dendrite $(u D)$. A THcontaining dendrite $(T H-D)$ is observed in direct apposition to the terminal with LE-LI (solid arrowheads) with no apparent glial intervention but lacking a synaptic contact. Autoradiographic exposure, 5 months. Scale bar, $0.5 \mu \mathrm{m}$. 
(a) 1
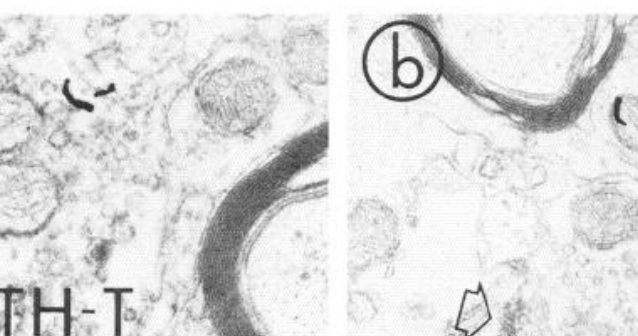

D. TH:T

$-25$

3

LEH FH-T

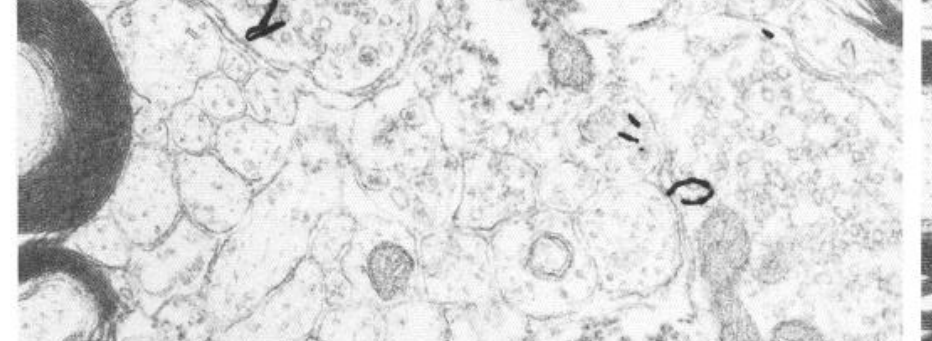

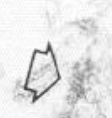

$6 x^{2}+25$
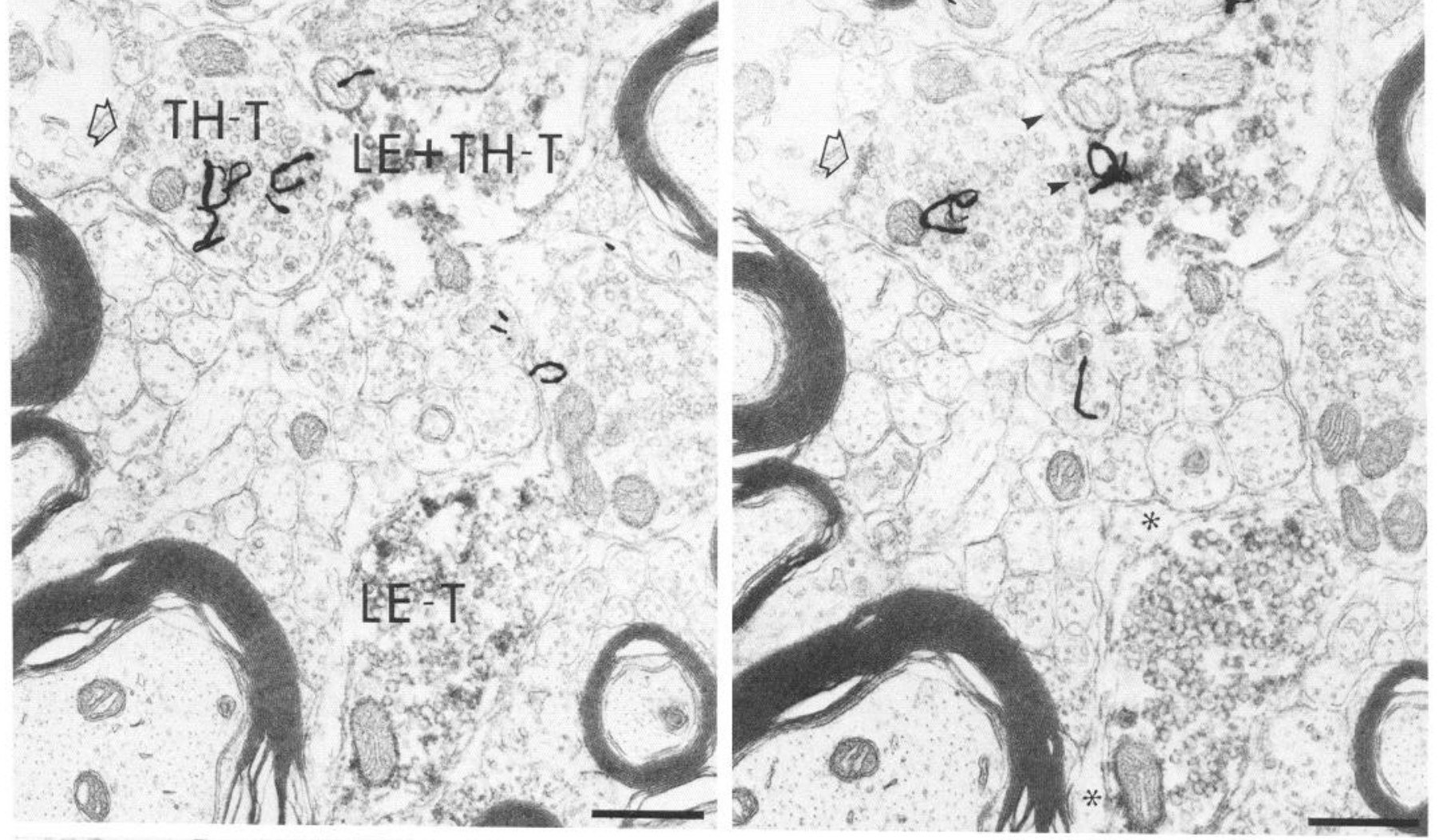

(c) 0.0

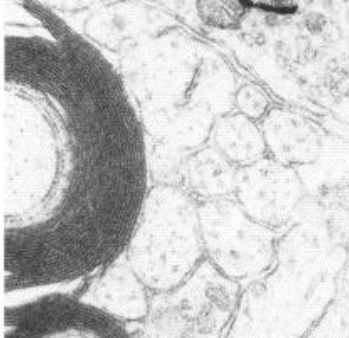

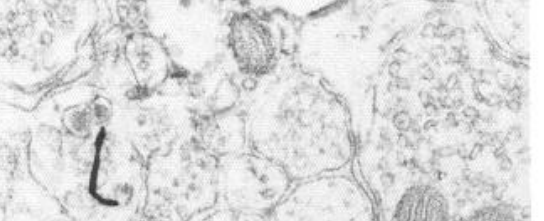

(9) $3: 2 ; 0$.

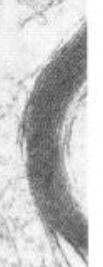

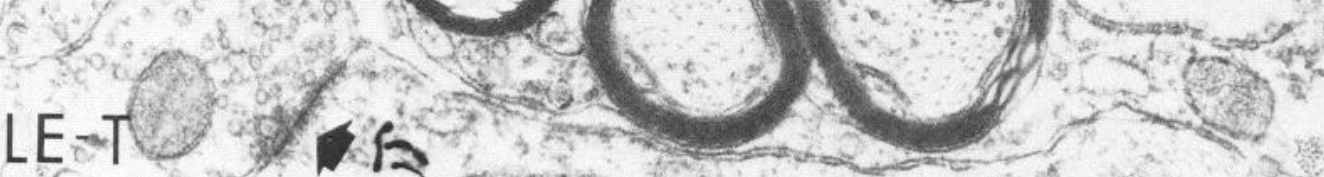
a $>?$

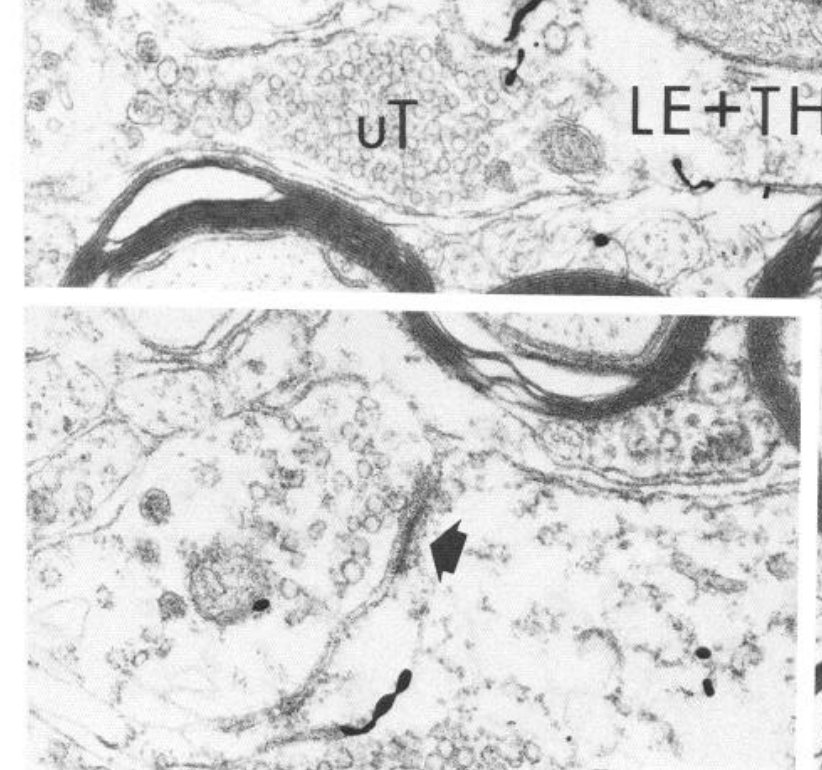

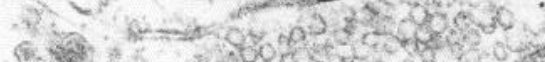
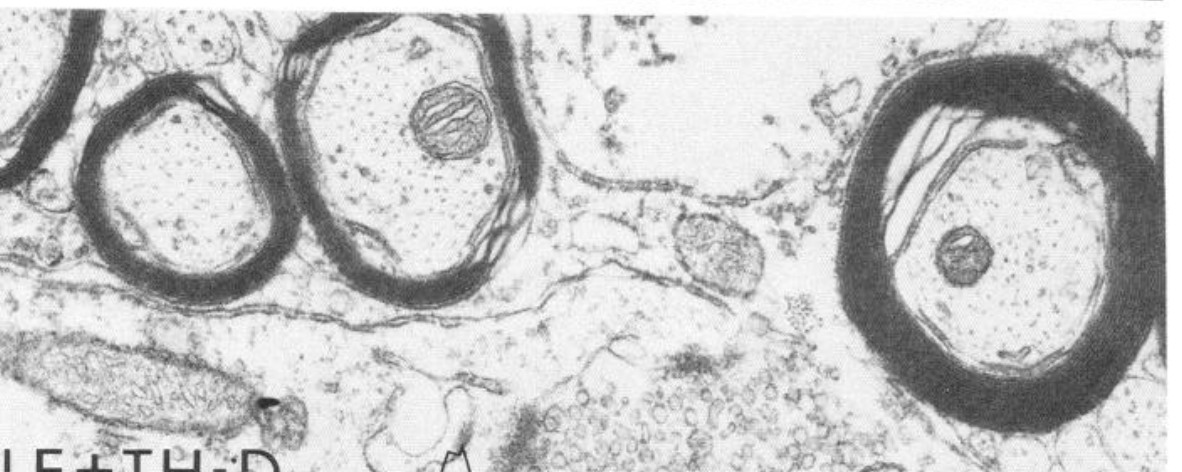

b.
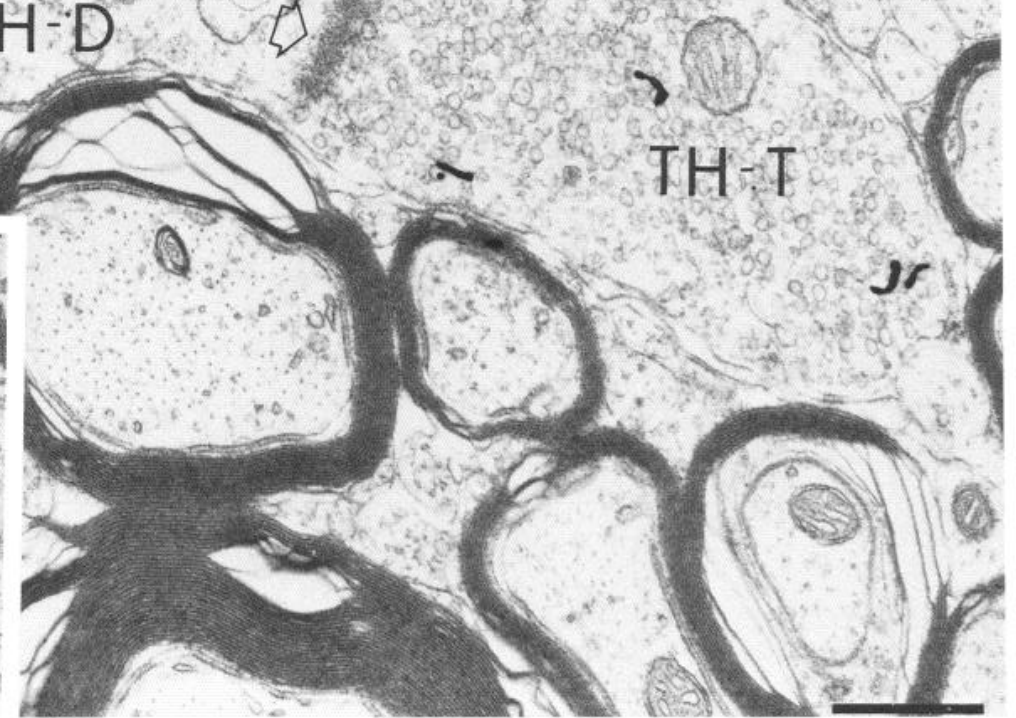


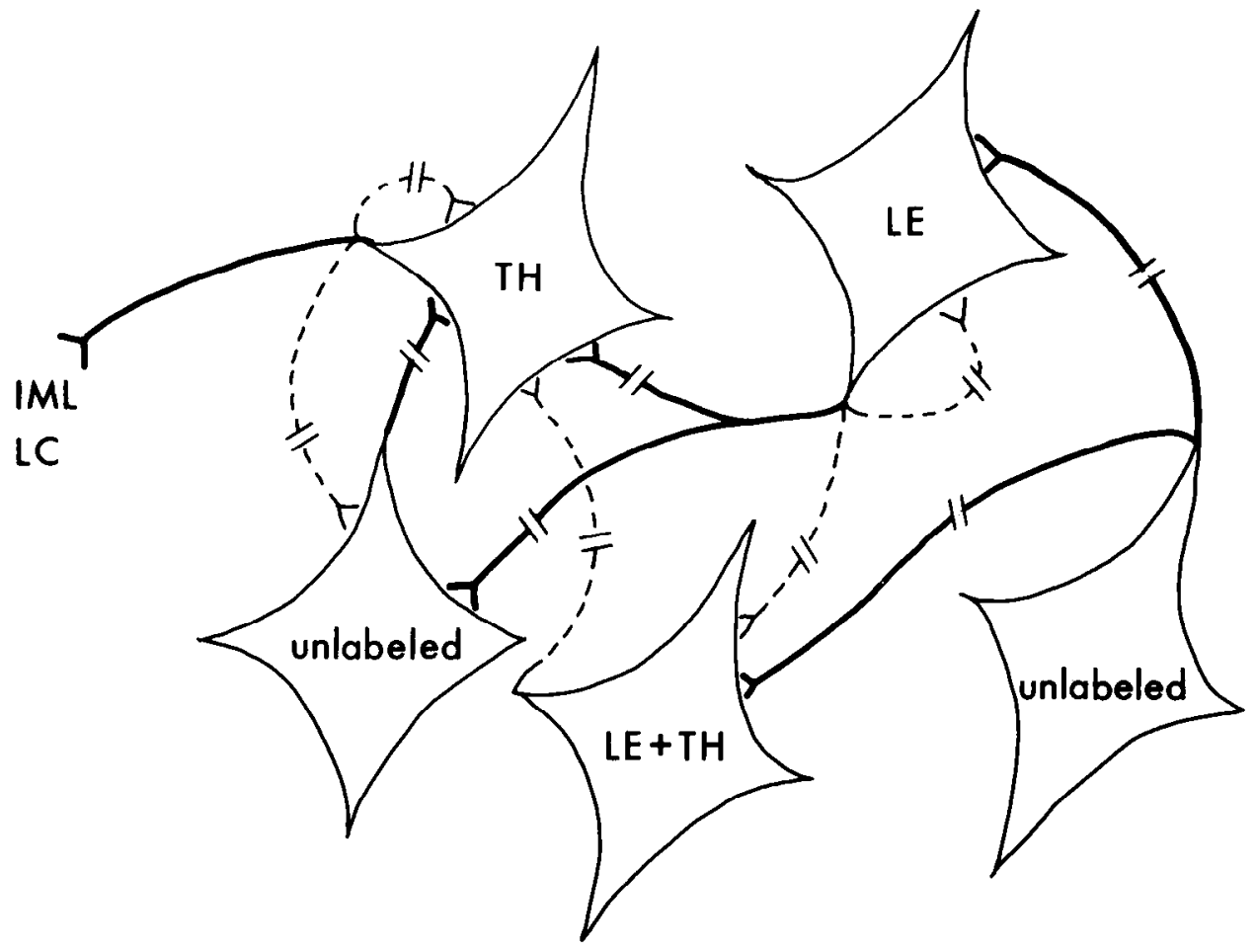

Figure 10. Leus-enkephalin ( $L E$-labeled cells receive a major synaptic input (heavy lines) from unlabeled terminals and a minor input (dashed lines) from cells with LE-LI, both of which may be either of intrinsic or extrinsic origin as indicated by $\|$. The enkephalinergic terminals form a nearly equal and major input to TH-labeled and unlabeled neurons and a minor input to neurons containing both LE-LI and TH-I $(L E+T H)$. A few of the terminals with LE-LI or LE-LI and TH-I synapse on $\mathrm{TH}$-labeled cells that also receive an input from a TH-containing terminal. THlabeled cells receive input primarily from unlabeled terminals but additionally receive input from $\mathrm{LE}, \mathrm{LE}+\mathrm{TH}$, or TH-containing terminals. The neurons with $\mathrm{TH}$ immunoreactivity innervate primarily unlabeled neurons but also TII and rarely LE-containing neurons (not shown). Catecholaminergic neurons (i.e., TH-containing), in particular the $\mathrm{Cl}$ adrenergic neurons, in the RVL project primarily to the IML of the spinal cord (Ross et al., 1984a; Milner et al., 1988c) and to the locus coeruleus (Aston-Jones et al., 1986). that the activities of catecholaminergic neurons in both the peripheral and CNS are modulated by opiates. In the PNS, exogenously applied enkephalins can inhibit the release of noradrenaline in several tissues via an interaction with presynaptic opiate receptors (Waterfield et al., 1977; Dubocovich and Langer, 1980). Within the brain, opiates not only have an overlapping distribution with that of many catecholamine cell groups (Khachaturian and Watson, 1982), but also may influence physiological function when applied to these areas. For example, injection of opiate receptor agonists into the caudal ventrolateral medulla including the Al noradrenergic area elicits an increase in AP and heart rate (Willette et al., 1984; Punnen and Sapru, 1985, 1986), while opiates and enkephalins inhibit locus coeruleus neuronal firing in a stereospecific naloxone-reversible fashion (Pepper and Henderson, 1980).

The target neurons of opioid terminals were not exclusively catecholaminergic (see schematic in Fig. 10). Some of the LEcontaining terminals synapse on similarly labeled neurons; a portion of these target neurons contain somatostatin and project to the NTS and to the IML of the spinal cord (Millhorn et al., 1987). However, a substantial number of the terminals with LELI formed junctions with perikarya and dendrites that lacked detectable immunoreactivity for LE or TH. This observation suggests that enkephalin also modulates other RVL neurons containing as yet unidentified transmitters, possibly SP, GABA, or ACh (Cuello and Kanazawa, 1978; Meeley et al., 1985; Milner et al., 1988b). SP-containing perikarya in the RVL receive symmetric contacts from non-SP and noncatecholaminergic terminals with similar morphological characteristics as those with LE-LI (Milner et al., 1988a). On the other hand, neurons in the KVL containing GABA are probably infrequent targets of enkephalinergic terminals. Local application of GABA agonists in the $\mathrm{Cl}$ area causes depressor responses (Willette et al., 1983; Ross et al., 1984a), which are probably mediated largely through inhibitory (i.e., symmetric) synapses on the adrenergic neurons (Milner et al., 1987b). If enkephalin were inhibiting a GABAergic neuron in the RVL, the net result should be excitation of the sympathoexcitatory reticulospinal neurons in the RVL, resulting in an elevation of $A P$ and heart rate, an effect opposite that observed when opiates are applied to the region (Florez and Mediavilla, 1977; Florez et al., 1982; Punnen and Sapru, 1986; Willette et al., 1989).

On the other hand, cholinergic neurons in the RVL could be an important target of terminals containing LE-LI. It is well established that opiate-containing terminals have an overlapping distribution with cholinergic neurons in several brain regions including the the hypoglossal nucleus and motor regions of the spinal cord (LaMotte and de Lanerolle, 1981; Connaughton et al., 1986). In a recent ultrastructural study of the RVL, we demonstrated that the majority of terminals that contacted

Figure 9. Multiple associations of terminals containing LE-LI. $a$ and $b$, Serial electron micrographs show a terminal which contains both LE-LI and TH-I in the same vicinity as terminals that are immunoreactive only for TH $(T H-T)$ or LE $(L E-T)$. The terminals with TH alone and LE + TH-I are closely apposed without any apparent glial intervention (arrowheads). The terminal containing LE-LI alone is partially separated from the surrounding neuropil by glial processes (asterisks). C. A LE-containing terminal ( $L E-T)$ forms a symmetric synapse (solid arrow) with a dendrite that is immunoreactive for both LE and TH $(L E+T H-D)$. The dendrite is also postsynaptic to a TH-labeled terminal $(T H-T)$ that forms an asymmetric synapse (open arrow). Inset, higher magnification through the LE-labeled terminal in an adjacent section. Autoradiographic exposure, 5 months. Scale bars, $0.5 \mu \mathrm{m}$. 
local cholinergic neurons were noncatecholaminergic and noncholinergic (Milner et al., 1988b). These terminals resembled the terminals with LE-LI in both morphology and synaptic associations. Further evidence for a potential opioid-cholinergic interaction in the RVL comes from the demonstration that the respiratory depression following local administration of opiates to the RVL is significantly attenuated by the systemic administration of the indirect cholinomimetic physostigimine (Willette et al., 1987). However, proof of a direct opioid-cholinergic interaction awaits demonstration by dual-labeling methods similar to the ones employed here.

\section{Convergence of terminals with $L E-L I$ and $T H-I$ on a common target and coexistence}

The demonstration that LE-LI and TH-I within the same or separate terminals that synapsed on common target neurons usually containing either TH or TH and LE supports physiological and pharmacological data showing that catecholaminergic (Aghajanian, 1978) as well as noncatecholaminergic neurons express receptive sites for both adrenergic and opioid receptors (Kunos et al., 1987). Moreover, microinjection of opiate agonists and $\alpha$-adrenergic agonists (e.g., clonidine) into or immediately adjacent to the $\mathrm{C} 1$-area produces a profound fall in AP (Florez and Mediavilla, 1977; Florez et al., 1982; Bousquet and Schwartz, 1983; Punnen and Sapru, 1986; Willette et al., 1989). These results could arise from the actions of opioids and catecholamines on common vasomotor neurons in the RVL, leading to reduced sympathetic outflow through depression of pathways to the IML of the spinal cord.

\section{References}

Aghajanian, G. K. (1978) Tolerance of locus coeruleus neurons to morphine and suppression of withdrawal response by clonidine. $\mathrm{Na}$ ture 276: 186-188.

Andrezik, J. A., V. Chan-Palay, and S. L. Palay (1981) The nucleus paragigantocellularis lateralis in the rat: Demonstration of afferents by the retrograde transport of horseradish peroxidase. Anat. Embryol. 161: 373-390.

Armstrong, D. M., V. M. Pickel, T. H. Joh, D. J. Reis, and R. J. Miller (1981) Immunocytochemical localization of catecholamine synthesizing enzymes and neuropeptides in area postrema and medial nucleus tractus solitarius of rat brain. J. Comp. Neurol. 196: 505-517.

Armstrong, D. M., C. A. Ross, V. M. Pickel, T. H. Joh, and D. J. Reis (1982) Distribution of dopamine, noradrenaline and adrenaline-containing cell bodies in the rat medulla oblongata: Demonstrated by the immunocytochemical localization of catecholamine biosynthetic enzymes. J. Comp. Neurol. 212: 173-187.

Aston-Jones, G., M. Ennis, V. A. Pieribone, W. T. Nickell, and M. T. Shipley (1986) The brain nucleus locus coeruleus: Restricted afferent control of a broad efferent network. Science 234: 734-737.

Beaudet, A. (1982) High resolution radioautography of central 5-hydroxytryptamine (5-HT) neurons. J. Histochem. Cytochem. 30:765768 .

Beaudet, A., and L. Descarries (1987) Ultrastructural identification of serotonin neurons. In Ultrastructural Identification of Monoamine at the Light Microscopical and Ultrastructural Level. H. W. M. Steinbusch, ed., pp. 265-313, Wiley, London.

Bousquet, P., and J. Schwartz (1983) Alpha adrenergic drugs: Pharmacological tools for the study of the central vasomotor control. Biochem. Pharmacol. 32: 1459-1465.

Cohen, R. S., R. K. Carlin, D. J. Grab, and P. Siekevitz (1982) Phosphoproteins in postsynaptic densities. Prog. Brain Res. 56: 49-76.

Connaughton, M., J. V. Priestley, M. V. Sofroniew, F. Eckenstein, and A. C. Cuello (1986) Inputs to motorneurones in the hypoglossal nucleus of the rat: Light and electron microscopic immunocytochemistry for choline acetyltransferase, substance $\mathrm{P}$ and enkephalins using monoclonal antibodies. Neuroscience 17: 205-224.

Cowan, W. M., D. I. Gottlieb, A. E. Hendrickson, J. L. Price, and T.
A. Woolsey (1972) The autoradiographic demonstration of axonal connections in the central nervous system. Brain Res. 37: 21-51.

Cuello, A. C., and I. Kanazawa (1978) The distribution of substance $\mathrm{P}$ immunoreactive fibers in the rat central nervous system. J. Comp. Neurol 178: 129-156.

DeMey, J., A. M. Lambert, A. S. Bajer, M. Moremas, and M. DeBrabander (1982) Visualization of microtubules in interphase and mitotic plant cells of Haenmantus endosperm with the immunogold staining method. Proc. Natl. Acad. Sci. USA 79: 1898-1902.

De Potter, W. P., E. P. Coen, and D. W. De Potter (1987) Evidence for the coexistence and corelease of [met] enkephalin and noradrenaline from sympathetic nerves of the bovine vas deferens. Neuroscience 20: $855-866$.

Dubocovich, M. L., and S. Z. Langer (1980) Pharmacological differentiation of presynaptic inhibitors, $\alpha$-adrenoreceptors and opiate receptors in the cat nictitating membrane. Br. J. Pharmacol. 70: 383393.

Elde, R., T. Hökfelt, O. Johansson,, and L. Terenius (1976) Immunohistochemical studies using antibodies to leucine-enkephalin: Initial observations on the nervous system of the rat. Neuroscience 1 . 349-351.

Fallon, J. H., and F. M. Leslie (1986) Distribution of dynorphin and enkephalin peptides in the rat brain. J. Comp. Neurol. 249: 293-336.

Finley, J. C. W., J. L. Maderdrut, and P. Petrusz (1981) The immunocytochemical localization of enkephalin in the central nervous system of the rat. J. Comp. Neurol. 198: 541-565.

Florez, J., and A. Mediavilla (1977) Respiratory cardiovascular effects of met-enkephalin applied to the ventral surface of the brainstem. Brain Res. 138: 585-596.

Florez, J., M. A. Hurle, and A. Mediavilla (1982) Respiratory responses to opiates applied to the medullary ventral surface. Life Sci. 31: 2189-2192.

Goodman, R. R., L. D. Fricker, and S. H. Snyder (1983) Enkephalins. In Brain Peptides, D. T. Krieger, M. J. Brownstein, and J. B. Martin, eds., pp. 827-849, Wiley, New York

Granata, A. R., Y. Numano, M. Kumada, and D. J. Reis (1986) A1 noradrenergic neurons tonically inhibit sympathoexcitatory neurons of the $\mathrm{Cl}$ area in rat brainstem. Brain Res. 377: 127-146.

Hancock, M. B., and A. P. Nicholas (1987) Oxytocin-immunoreactive projections onto medullary adrenaline neurons. Brain Res. 18:213219.

Hökfelt, T., K. Fuxe, M. Goldstein, and O. Johansson (1974) Immunohistochemical evidence for the existence of adrenaline neurons in the rat brain. Brain Res. 66: 235-251.

Hökfelt, T., R. Elde, O. Johansson, L. Terenius, and L. Stein (1977) The distribution of enkephalin-immunoreactive cell bodies in the rat central nervous system. Neurosci. Lett. 5: 25-31.

Hökfelt, T., M. Goldstein, K. Fuxe, O. Johansson, A. Verhofstad, H. Steinbusch, B. Penke, and J. Vargas (1980) Histochemical identification of adrenaline containing cells with special reference to neurons. In Central Adrenaline Neurons: Basic Aspects and their Role in Cardiovascular Function, K. Fuxe, M. Goldstein, T. Hökfelt, eds., pp. 19-47, Pergamon, New York.

Hunt, S. P., J. S. Kelly, and P. C. Emson (1980) The electron microscopic localization of methionine-enkephalin within the superficial layers (I and II) of the spinal cord, Neuroscience 5: 1871-1890.

Joh, T. H., and M. Goldstein (1973) Isolation and characterization of multiple forms of phenylethanolamine $\mathrm{N}$-methyltransferase. Mol. Pharmacol. 9: 117-129.

Joh, T. H., and M. E. Ross (1983) Preparation of catecholamine synthesizing enzymes as immunogen for immunocytochemistry. In Immunocytochemistry, Vol. 3, Oxford IBRO Handbook Series, A. C. Cuello, ed., pp. 121-138, Wiley, New York.

Kalia, M., K. Fuxe, and M. Goldstein (1985a) Rat medulla oblongata. II. Dopaminergic, noradrenergic ( $\mathrm{A} \perp$ and $\mathrm{A} 2$ ) and adrenergic neurons, nerve fibers and presumptive terminals processes. J. Comp. Neurol. 233: 308-332.

Kalia, M., K. Fuxe, and M. Goldstein (1985b) Rat medulla oblongata. III. Adrenergic ( $\mathrm{Cl}$ and $\mathrm{C} 2$ ) neurons, nerve fibers and presumptive terminal processes. J. Comp. Neurol. 233: 333-349.

Kalia, M., D. J. Woodward, W. K. Smith, and K. Fuxe (1985c) Rat medulla oblongata. IV. Topographical distribution of catecholaminergic neurons with quantitative three-dimensional computer reconstruction. J. Comp. Neurol. 233: 350-364.

Khachaturian, H., and S. J. Watson (1982) Some perspectives on 
monoamine-opioid peptide interaction in rat central nervous system Brain Res. Bull 9: 441-462.

Krnjevic', K. (1976) Inhibitory action of GABA and GABA-mimetric on vertebrate neurons. In GABA in Nervous System Function, E. Roberts, T. N. Chase, and D. B. Tower, eds., pp. 269-282, Raven, New York

Kunos, G., R. Mosqueda-Garcia, and J. A. Mastrianni (1987) Endorphinergic mechanism in the central cardiovascular and analgesic effects of clonidine. Can. J. Physiol. Pharmacol. 65: 1624-1632

LaMotte, C., and N. C. de Lanerolle (1981) Human spinal neurons: Innervation by both substance $\mathrm{P}$ and enkephalin. Neuroscience 6 : 247-266.

Larsson, L.-I. (1981) A novel immunocytochemical model system for specificity and sensitivity screening of antisera against multiple antigens. J. Histochem. Cytochem. 29: 408-410.

Ljungdahl, A., T. Hökfelt, and G. Nilsson (1978) Distribution of substance P-like immunoreactivity in the central nervous system of the rat. I. Cell bodies and nerve terminals. Neuroscience 3: 861-943.

Masurovsky, E. R., and R. P. Bunge (1968) Fluroplastic coverslips for long-term nerve tissue culture. Stain Technol. 43: 161-165.

Meeley, M. P., D. A. Ruggiero, T. Ishitsuka, and D. J. Reis (1985) Intrinsic $\gamma$-aminobutyric acid neurons in the nucleus of the solitary tract and the rostral ventrolateral medulla of the rat: An immunocytochemical and biochemical study. Neurosci. Lett. 58: 83-89.

Millhorn, D. E., K. Seroogy, T. Hökfelt, L. C. Schmued, L. Terenius, A. Buchan, and J. C. Brown (1987) Neurons of the ventral medulla oblongata that contain both somatostatin and enkephalin immunoreactivities project to nucleus tractus solitarii and spinal cord. Brain Res. 424: 99-108.

Milner, T. A., V. M. Pickel, D. H. Park, T. H. Joh, and D. J. Reis (1987a) Phenylethanolamine N-methyltransferase-containing neurons in the rostral ventrolateral medulla of the rat: I. Normal ultrastructure. Brain Res. 411: 28-45.

Milner, T. A., V. M. Pickel, J. Chan, V. J. Massari, W. H. Oertel, D. H. Park, T. H. Joh, and D. J. Reis (1987b) Phenylethanolamine $\mathrm{N}$-methyltransferase-containing neurons in the rostral ventrolateral medulla: II. Synaptic relationships with $\mathrm{G} \Lambda \mathrm{B} \Lambda$ ergic terminals. Brain Res. 411: 46-57.

Milner, T. A., V. M. Pickel, C. Abate, T. H. Joh, and D. J. Reis (1988a) Ultrastructural characterization of substance $P$-containing neurons in the rostral ventrolateral medulla in relation to neurons containing catecholamine synthesizing enzymes. J. Comp. Neurol. 270:427-446

Milner, T. A., V. M. Pickel, R. Giuliano, and D. J. Reis (1988b) Ultrastructural localization of choline acetyltransferase in the rat rostral ventrolateral medulla: Evidence for major synaptic interactions with non-catecholaminergic neurons. Brain Res. (in press).

Milner, T. A., S. Morrison, and D. J. Reis (1988c) Phenylethanolamine $\mathrm{N}$-methyltransferase-containing terminals synapse directly on sympathetic preganglionic neurons in the rat. Brain Res. 448: 205-222.

Milner, T. A., C. Abate, D. J. Reis, and V. M. Pickel (1989) Ultrastructural localization of phenylcthanolaminc N-methyltransferaselike immunoreactivity in the rat locus coeruleus. Brain Res. 478:115.

Murakami, S., H. Okamura, C. Yanaihara, N. Yanaihara, and Y. Ibata (1987) Immunocytochemical distribution of Met-enkephalin-Arg ${ }^{6}$ Gly'-Leu $^{8}$ in the rat lower brainstem. J. Comp. Neurol. 261: 193208.

Neuman, B., G. J. Wiedeman, R. Fischer-Colbrie, M. Schrober, G. Sperk, and H. Winkler (1984) Biochemical and functional properties of large and small dense-core vesicles in sympathetic nerves of rat and $o x$ vas deferens. Neuroscience 13: 921-931.

Ordronneau, P., P. B. M. Lindstrom, and P. Petrusz (1981) Four unlabeled antibody bridge techniques. A comparison. J. Histochem. Cytochem. 29: 1397-1404.

Pepper, C. M., and G. Henderson (1980) Opiates and opioid peptides hyperpolarize locus coeruleus neurons in vitro. Science 209: 394-396.

Pickel, V. M., T. H. Joh, D. J. Reis, S. E. Leeman, and R. J. Miller (1979) Electron microscopic localization of substance P and enkephalin in axon terminals related to dendrites of catecholaminergic neurons. Brain Res. 160: 387-400.

Pickel, V. M., J. Chan, and T. A. Milner (1986) Autoradiographic detection of ${ }^{125}$ I-secondary antiserum: A sensitive light and electron microscopic labeling method compatible and peroxidase immunocytochemistry for dual localization of neuronal antigens. H. Histochem. Cytochem. 34: 707-718.

Pickel, V. M., T. H. Joh, and J. Chan (1988a) Substance P in the rat nucleus accumbens: Ultrastructural localization in axon terminals and their relation to dopaminergic afferents. Brain Res. 444: 247-264.

Pickel, V. M., A. C. Towle, T. H. Joh, and J. Chan (1988b) Gammaaminobutyric acid in the medial rat nucleus accumbens: Ultrastructural localization in neurons receiving monosynaptic input from catecholaminergic afferents. J. Comp. Neurol. 272: 1-14.

Pickel, V. M., J. Chan, and T. A. Milner (1989) Cellular basis for interactions between central opioids and catecholamines. II. Nuclei of the solitary tracts. J. Neurosci. (in press).

Priestley, J. V. (1981) Ultrastructural localization of substance $\mathbf{P}$ and enkephalin in the substantia gelatinosa of the spinal trigeminal nucleus. Br. J. Pharmacol. 74: 893-894.

Punnen, S., and H. N. Sapru (1985) Blockade of cholinergic receptors in the $\mathrm{Cl}$ area abolishes hypertensive response to opiates in the $\mathrm{Al}$ area of the ventrolateral medulla. Brain Res. 336: 180-186.

Punnen, S., and H. N. Sapru (1986) Cardiovascular responses to medullary microinjections of opiate agonists in urethane-anesthetized rats. J. Cardiovasc. Pharmacol. 8: 950-956.

Reis, D. J., S. Morrison, and D. A. Ruggiero (1988) The Cl area of the brainstem in tonic and reflex control of blood pressure. Hypertension Suppl. 11: I8-I13.

Reynolds, E. S. (1963) The use of lead citrate at high $\mathrm{pH}$ as an electronopaque stain in electron microscopy. J. Cell Biol. 17: 208.

Ross, C. A., D. A. Ruggiero, T. H. Joh, D. H. Park, and D. J. Reis (1984a) Rostral ventrolateral medulla: Selective projections to the thoracic autonomic cell column from the region containing $\mathrm{C} 1$ adrenaline neurons. J. Comp. Neurol. 228: 168-184.

Ross, C. A., D. A. Ruggiero, D. H. Park, T. H. Joh, A. F. Sved, J. Fernandez-Pardal, J. M. Saavedra, and D. J. Reis (1984b) Tonic vasomotor control by the rostral ventrolateral medulla: Effect of electrical or chemical stimulation of the area containing $\mathrm{Cl}$ adrenaline neurons on arterial blood pressure, heart rate and plasma catecholamines and vasopression. J. Neurosci. 4: 474-494.

Ross, C. A., D. A. Ruggiero, and D. J. Reis (1985) Projections from the nucleus of the tractus solitarii to the rostral ventrolateral medulla. J. Comp. Neurol. 242: 511-534.

Ruggiero, D. A., R. Giuliano, R. Stornetta, M. Anwar, H. Baker, and D. J. Reis (1988) Anatomical substrates for cholinergic autonomic regulation. J. Comp. Neurol. (in press).

Salpeter, M. M., H. C. Fertuck, and E. E. Salpeter (1977) Resolution in electron microscope autoradiography. III. Iodine-125, the effect of heavy metal staining, and reassessment of critical parameters. J. Cell Biol. 72: 161-173.

Salpeter, M. M., F. A. McHenry, and E. E. Salpeter (1978) Resolution in electron microscope autoradiography. IV. Application to analysis of autoradiographs. J. Cell Biol. 76: 127-145.

Sar, M., W. E. Stumpf, R. J. Miller, K. Chang, and P. Cuatrecasas (1978) Immunohistochemical localization of enkephalin in rat brain and spinal cord. J. Comp. Neurol. 182: 17-38.

Smith, A. P., and N. M. Lee (1988) Pharmacology of dynorphin. Annu. Rev. Pharmacol. Toxicol. 28: 123-140.

Sternberger, L. A. (1979) Immunocytochemistry, Wiley, New York.

Tucker, D. C., C. B. Saper, D. A. Ruggiero, and D. J. Reis (1987) Organization of central adrenergic pathways: I. Relationships of ventrolateral medullary projections to the hypothalamus and spinal cord. J. Comp. Neurol. 259: 591-603.

Uchizono, K. (1965) Characteristics of excitatory and inhibitory synapses in the CNS of the cat. Nature 207: 642-643.

Voorn, P., and R. M. Buijs (1983) An immuno-electron microscopical study comparing vasopressin, oxytocin, substance $P$ and enkephalin containing nerve terminals in the nucleus of the solitary tract of the rat. Brain Res. 270: 169-173.

Waterfield, A. A., R. W. J. Smokeum, J. Hughes, H. W. Kosterlitz, and G. H. Henderson (1977) In vitro pharmacology of the opioid peptides, enkephalins and endorphins, Eur. J. Pharmacol. 43: 107-116.

Willette, R. N., A. J. Kreiger, P. P. Barcas, and H. N. Sapru (1983) Medullary $\gamma$-aminobutyric acid (GABA) receptors and the regulation of blood pressure in the rat. J. Pharmacol. Exp. Ther. 226: 893-899.

Willette, R. N., S. Punnen, A. J. Krieger, and H. N. Sapru (1984) Hypertensive response following stimulation of opiate receptors in the caudal ventrolateral medulla. Neuropharmacology. 23: 401-406.

Willette, R. N., B. M. Coorley, and H. N. Sapru (1987) Activation of cholinergic mechanisms in the medulla oblongata reverse intravenous opioid-induced respiratory depression. J. Pharmacol. Exp. Ther. 240: 352-358.

Willette, R. N., S. Morrison, H. N. Sapru, and D. J. Reis (1989) In- 
halation anesthetic-opioid interaction: Expression of opioid actions in the medullary rostral ventrolateral reticular nucleus. Neuropharmacology (in press).

Williams, R. G., and G. J. Dockray (1983) Distribution of enkephalinrelated peptides in rat brain: Immunohistochemical studies using antisera to met-enkephalin and met-enkephalin $\mathrm{Arg}^{6} \mathrm{Phe}^{7}$. Neuroscience 9: $563-586$.
Zamir, N., and R. Quirion (1985) Dynorphinergic pathways of Leuenkephalin production in the rat brain. Neuropeptides 5: 441-444.

Zamir, N., E. Weber, M. Palkovits, and M. Brownstein (1984) Differential processing of prodynorphin and proenkephalin in specific regions of the rat brain. Proc. Natl. Acad. Sci. USA 81: 6886-6889. 